\title{
Social context shapes cognitive abilities: associative memories are modulated by fight outcome and social isolation in the crab Neohelice granulata
}

\author{
M. Jimena Santos ${ }^{1,2} \cdot$ Santiago A. Merlo ${ }^{1,2} \cdot$ Laura Kaczer $^{1,2} \cdot$ Maria E. Pedreira $^{1,2}$
}

Received: 11 July 2020 / Revised: 9 February 2021 / Accepted: 15 February 2021 / Published online: 31 March 2021

(c) The Author(s), under exclusive licence to Springer-Verlag GmbH Germany, part of Springer Nature 2021

\begin{abstract}
Cognitive abilities of an animal can be influenced by distinct social experiences. However, the extent of this modulation has not been addressed in different learning scenarios: are all tasks similarly affected by social experiences? In the present study, we analyzed the effect of social dominance in aversive and appetitive memory processes in the crab Neohelice granulata. In addition, we studied the influence of social isolation on memory ability. Social dominance experiments consisted of an agonistic phase immediately followed by a memory phase. During the agonistic phase, matched pairs of male crabs were staged in 10-min encounters and the dominant or subordinate condition of each member of the dyad was determined. During the memory phase, crabs were trained to acquire aversive or appetitive memory and tested $24 \mathrm{~h}$ later. Results showed that the agonistic encounter can modulate long-term memory according to the dominance condition in such a way that memory retention of subordinates results higher than their respective dominant. Remarkably, this result was found for both aversive and appetitive memory tasks. In addition, we found that isolated animals showed no memory retention when compared with animals that remained grouped. Altogether this work emphasizes the importance of social context as a modulator of cognitive abilities.
\end{abstract}

Keywords Fight outcome $\cdot$ Social isolation $\cdot$ Aversive memory $\cdot$ Appetitive memory $\cdot$ Neohelice granulata $\cdot$ Consolidation $\cdot$ Exploratory activity

\section{Introduction}

Animals live in a complex social environment and the interactions between members of a group mold not only the way the individuals adapt to limited resources but also their behavior.

Interaction within members of their species can present certain advantages and disadvantages. On the one hand, they can detect/repel predators more easily, defend better, locate

Laura Kaczer and Maria E. Pedreira have contributed equally to this work.

Maria E. Pedreira

mpedreira@fbmc.fcen.uba.ar

1 Instituto de Fisiología, Biología Molecular y Neurociencias (IFIBYNE)-CONICET, CONICET, 1428 Buenos Aires, Argentina

2 Facultad de Ciencias Exactas y Naturales, Universidad de Buenos Aires, Buenos Aires, Argentina food and resources (Nelson 2005). On the other hand, as resources are generally limited, this could lead to competition between members of a group (Huntingforda 2013). Thus, agonistic interactions appear as a consequence of a conflict arising in terms of resource acquisition (food, territory, access to couple) which is ultimately associated with individual fitness (Arnott and Elwood 2009; Eggert et al. 2008).

In the last years, interest in studying how social context can shape behavior has increased. Several reports revealed that individual dominance status can influence other nonsocial behaviors (Hofmann et al. 1999; Keeney and Hogg 1999; Maruska and Fernald 2012; May and Mercier 2007; Robson and Miles 2000; Yeh et al. 1996, 1997). For instance, in sea lobsters, an animal's response to a tactile stimulus differed according to its status: dominants presented an orientation response towards it, while subordinates elicited an escape response (Song et al. 2006). Further, in an African cichlid fish, sensorimotor gating of startle behavior, a phenomenon associated with information processing, showed 
differential modulation by social isolation and social defeat (Adelman et al. 2019). Moreover, the authors revealed differences in locomotion and anxiety-like behavior: dominant females traveled shorter distances while subordinate females showed anxiety-related behavior.

Living in a complex social environment can require cognitive abilities to reach benefits (Langley, et al. 2018a, b; Trannoy and Kravitz 2015). Cognitive skills can be understood as the ability of animals to acquire, process, integrate information, and consequently, modify their behavior based on environmental requirements. An individual's position in a social hierarchy not only determines individual fitness in terms of resource access but also learning opportunities, turning into a relevant factor that might influence performance in cognitive tasks (Bunnell et al. 1979; Chalmeau and Gallo 1993). In this sense, in the last years, a new area has emerged intending to study the effects induced by dominance relationships in processes, such as learning and memory. (Barnard and Luo 2002; Boogert et al. 2006; Fitchett and Collins 2005; Francia et al. 2006; Kaczer et al. 2007; Langley et al. 2018a, b). Thus, cognitive skills have not only been studied regarding individual fitness but also taking into account the complex social context in which the environment is learned and interpreted (Humphrey 1976).

A series of studies carried out on different vertebrate species showed that performance in a learning task was related to an animal's level of aggressiveness, expressed by its status as winner or loser of an agonistic encounter, or by its rank within a social hierarchy. In general, studies have found a positive relationship between aggression and cognitive abilities, that is, more aggressive or dominant animals perform better in different cognitive tasks (Boogert et al. 2006; Fitchett and Collins 2005; Francia et al. 2006; Langley et al. 2018a, b; Colas-Zelin et al. 2012; Spritzer et al. 2004). However, there are a few studies where a lower social rank is associated with an improvement in learning and memory tasks (Barnard and Luo 2002; Bunnell et al. 1979; Keynan et al. 2015; Matzel et al. 2017; Monlen et al. 2015). This leads to speculation that memory modulation may be linked not only to the fight outcome per se but also to its duration and probably to the type of memory under evaluation (Keynan et al. 2016).

Invertebrates are an outstanding model system for the study of aggression. In particular, many investigations have focused on decapod crustaceans since they present highly structured and easily evocable behavioral systems. This offers unique opportunities to quantify the level of aggression, explore the mechanisms that underlie dominance relationships formation/maintenance, investigate the dynamic properties of hierarchical establishment as well as the neurochemical and genetic mechanisms involved in these types of behaviors (Kravitz and Huber 2003). Furthermore, invertebrates have provided important insights into the understanding of other non-social behaviors, such as learning and memory. Characterized as 'simple systems' regarding nervous complexity, they evoke a wide range of behavioral patterns as well as behavioral flexibility in response to distinct input stimuli (Burrell and Sahley 2001). Altogether these aspects have contributed to the emergence of these models for the study of cognitive processes which are highly conserved throughout the animal kingdom.

The semiterrestrial burrowing crab Neohelice granulata is a key species inhabiting the intertidal zone of estuaries, salt marshes, and mangroves of the south-western Atlantic Ocean. It is distributed at high-density populations in habitats of varying salinity, temperature, and tidal patterns, generating extensive beds of burrows (Spivak et al. 1994; Spivak 1997). Burrows reach high densities, up to 60 burrows per $\mathrm{m}^{2}$ (Iribarne et al. 1997), and vary in size and form depending on the habitat where they are constructed. Its main predator is the crab-eater gull, thus stimuli passing above the animal's visual horizon are interpreted as potentially dangerous.

Neohelice granulata is considered an emergent animal model since during the last 30 years it had been the subject of extensive research in distinct but also overlapping areas: ecology, physiology, toxicology, behavior and learning and memory processes (Spivak 2010; Luppi and Rodriguez 2020; Rodriguez and Luppi 2020). Aggressive behavior has been observed in the field and well characterized in laboratory conditions. Field analysis of social behaviors has revealed that crabs get involved in agonistic behavior for burrow defense, a trait that is ultimately associated with matting success (Moyano et al. 2012; Sal Moyano et al. 2016). Moreover, previous work in our laboratory found that sizematched male crabs display conspicuous agonistic behavior and establish winner-loser relationships that were stable over successive encounters (Kaczer et.al. 2007; Pedetta et al. 2010). However, no ritualized aggression was shown throughout the fights. Moreover, no changes in the contest intensity from a first to a second encounter were observed, contrasting with a typical case of dominance status. These findings led to propose the hypothesis that size-matched fights in Neohelice granulata would be resolved according to the contestants' level of aggressiveness. Taken together the extensive research in Neohelice granulata, not only in processes, such as learning and memory, but also in agonistic interactions, turn it into an excellent model to evaluate how social interactions could modulate cognitive abilities.

In this sense, the influence of dominance status on performance in a learning task was analyzed in a previous work in the crab Neohelice granulata (Kaczer et al. 2007). The memory paradigm was based on the association between a context and a visual danger stimulus (VDS). The experimental design consisted of mainly two phases: an agonistic phase where the dominance condition was established and a 
mnesic phase where the animals were trained and evaluated under the context-signal memory paradigm. Critically, the agonistic encounter took place $48 \mathrm{~h}$ before the mnesic phase. Results showed that subordinate crabs have significantly higher memory retention than their respective dominant. Nonetheless, in the previous study, it was not possible to analyze the direct effect of the fight outcome on the escape response, memory acquisition, and consolidation, because there was a $48 \mathrm{~h}$ interval between the agonistic and memory phase.

In the present work, we aim to study the direct effect of social experiences on distinct cognitive abilities in the crab. For that purpose, the time window between the agonistic phase and the mnesic phase was shortened allowing us to study the immediate consequence of fight outcome in the acquisition and/or consolidation of associative memories. First, we addressed whether there were differences between dominant and subordinates in exploratory behavior and the reactivity to a visual danger stimulus, Second, we evaluated the putative modulatory effect on learning and memory in an aversive memory paradigm. Moreover, to further understand how differences in the social context can shape mnesic abilities, we analyzed to what extent social isolation could modulate aversive memory formation. Finally, we also studied the modulatory effect of fights on an appetitive memory exploring the consequence of the agonistic encounter in the framework of a memory with a positive valance.

\section{Materials and methods}

\section{Animals}

Adult males Neohelice granulata (formerly known as Chasmagnathus granulatus, Crustacea, Grapsidae) intertidal crabs, $2.6-2.9 \mathrm{~cm}$ across the carapace, weight $17 \pm 0.2 \mathrm{~g}$ $(n=60)$, were collected from water $<1 \mathrm{~m}$ deep in the estuarine coasts of San Clemente del Tuyu, Argentina, and transported to the laboratory where they were lodged in plastic tanks $(30 \times 45 \times 20 \mathrm{~cm})$ filled to $0.5 \mathrm{~cm}$ depth with diluted (12\%, $\mathrm{pH}$ 8.2-8.4) marine water (prepared from Red Sea Salt, USA), to a density of 20 crabs per tank. The holding room was maintained on a $12 \mathrm{~h}$ light-dark cycle (lights were on between $7 \mathrm{AM}$ and $7 \mathrm{PM}$ ). The temperature of both holding and experimental rooms was maintained within a range of $22-24^{\circ} \mathrm{C}$. Experiments were carried out on day 7 after the arrival of the animals. Each crab was used in only one experiment. Experimental procedures are in compliance with the National Institutes of Health Guide for Care and Use of Laboratory Animals (USA) and the Argentinean guidelines on the ethical use of animals. All efforts were made to minimize animal suffering and to reduce the number of animals used.

This work was approved by our research institution.

\section{Experimental design}

All experiments are detailed in Table 1.

Experiment 1: Effect of fight outcome on explorative activity.

Experiment 2, 3 and 4: Effect of fight outcome on an aversive memory paradigm.

Experiment 5: Effect of social isolation on an aversive memory paradigm.

Experiment 6: Effect of fight outcome on an appetitive memory paradigm.

Each experiment consisted of two stages: the agonistic phase (establishment of the dominance condition) or social isolation phase, and the memory phase (acquisition and assessment of memory) or exploratory activity evaluation phase.

In all the experiments showed throughout this work, the memory phase/exploratory activity evaluation phase was carried out immediately after confrontations/social isolation (Table 1, Fig. 1a, experimental time scale). This experimental design marks a substantial difference with a previous work (Kaczer 2007) in which the fights were carried out $48 \mathrm{~h}$ before the memory phase.

\section{Experimental procedures}

\section{Experiment 1. Effect of fight outcome on explorative activity}

Agonistic phase One day after arrival to the laboratory, animals were isolated in individual opaque containers without food, for at least 6 days before the initiation of confrontations. Previous works with other species have shown

Table 1 Experimental design

\begin{tabular}{lll}
\hline Experimental design & Social context & Memory phase \\
\hline Experiment 1: Effect of fight outcome on exploratory activity & Agonistic encounter & Exploratory activity \\
Experiment 2, 3 and 4: Effect of fight outcome on aversive memory & Agonistic encounter & Aversive memory paradigm \\
Experiment 5: Effect of social isolation on aversive memory & Social Isolation & Aversive memory paradigm \\
Experiment 6: Effect of fight outcome on appetitive memory & Agonistic encounter & Appetitive memory paradigm \\
\hline
\end{tabular}


A
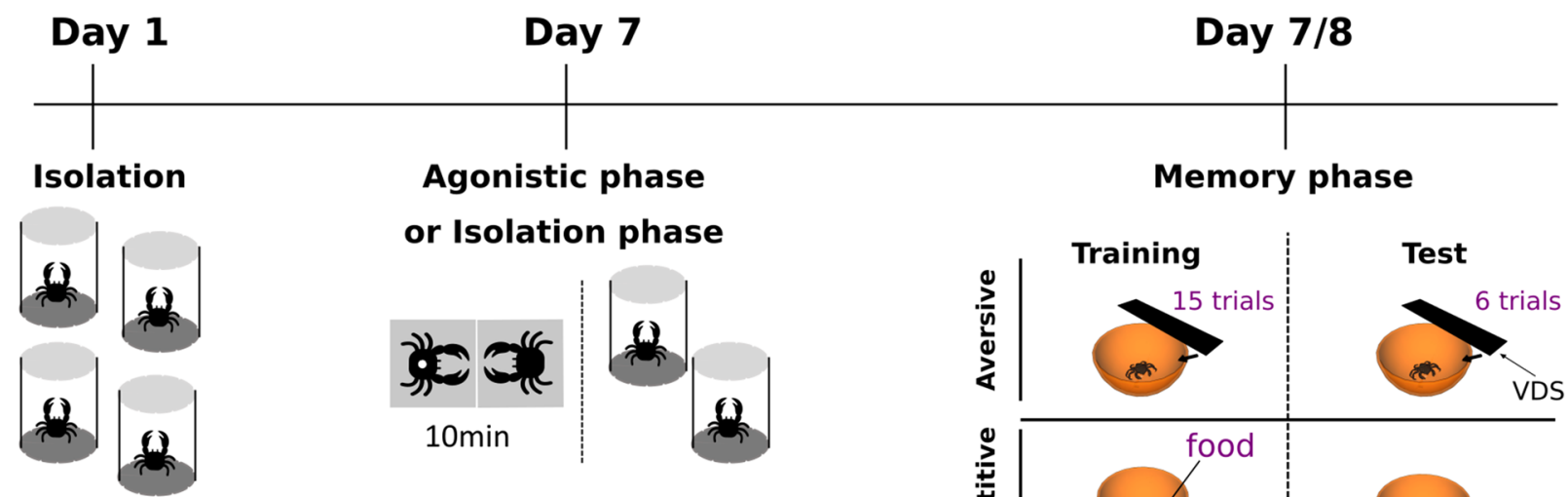

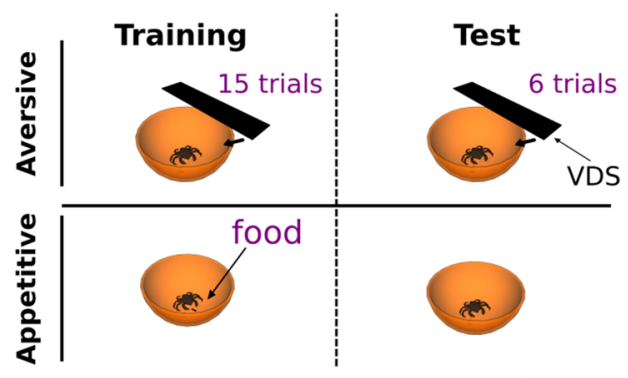

Day 7

Day 8
B

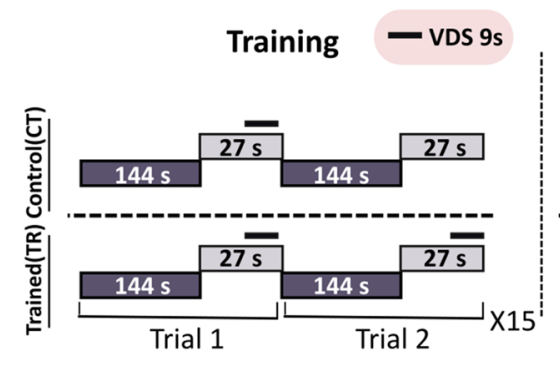

Aversive memory phase

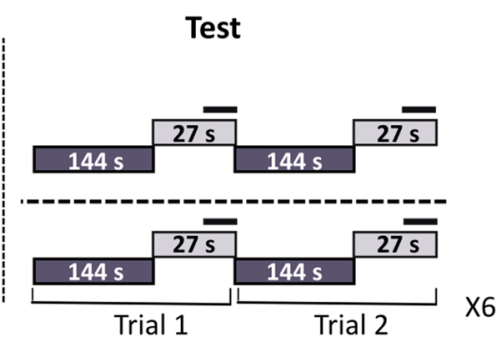

C Appetitive memory phase

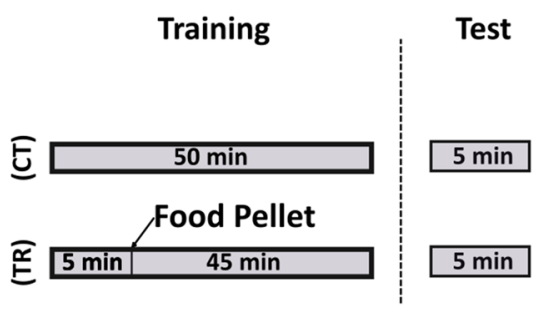

Fig. 1 a Experimental time scale. b Aversive experimental protocol. Training and test: Differences in rectangles colors stand for the light shift between visual danger stimulus (US) trials. c Appetitive experi- mental protocol. Training and test: the duration of each session and the time of pellet administration in the trained group is specified that this isolation period can increase the aggressiveness (Cromarty et al. 1999; Valzelli 1973) and also remove any prior social effects (Guiasu and Dunham 1999; Karavanich and Atema 1998). We staged dyadic encounters between male crabs matched to within $1 \mathrm{~mm}$ for both carapace width and claw length, which increased aggression during the fight (Vye et al. 1997). One member of the dyad was marked with a small dot of white-out (BIC) on its carapace. Each animal of a pair was moved from its respective individual container to the opposite sides of an observation arena, where the encounter took place. The encounter duration was 10 min since previous observations showed limited interactions after such period. When the encounter finished, crabs were moved from the arena back to their respective individual containers. We performed one encounter for each dyad. The arena consisted of an opaque plastic box $(12.5 \times 25 \times 15 \mathrm{~cm})$, illuminated from above. We worked with 10 arenas and recorded ten encounters simultaneously employing two Sony digital camcorders DCR-TRV22, and a laptop computer used as an event recorder. A customized software allowed us to record the time each animal spent in each category of agonistic behavior and provided a temporal curve of the interactions during the encounter.

Categories of agonistic behavior. As previously described in other reports ( Kaczer et al. 2007; Pedetta et al. 2010), the following categories of agonist behavior were defined to evaluate the animals' performance during the encounters. Approach stands for a walk of the animal towards the opponent, either facing it or not. Attack stands for sudden movements of one animal towards another that lead to physical contact. It includes diverse kinds of touching between the chela(e) and the opponent body, as jabbing (vigorous and rapid touching), pushing or enveloping (a movement of one or both chelae to embrace a conspecific). Retreat stands for the movement of one animal away from the other in response to an attack or approach; including escapes, i.e., quick retreats. Approaches and attacks are considered as "dominant acts", while retreats 
as "submissive acts". Apart from these three items of agonistic behavior, we distinguished a fourth category of behavior, the "non-agonistic behaviors", that includes wandering (movements not oriented towards their opponents) and resting.

Evaluation of agonistic performance. To describe the outcome of the agonistic encounter, we used two indexes. The first one is named individual dominance level (IDL), which stands for the difference between the total time of dominant acts, approaches (AP) plus attacks (AT), and the total time of submissive acts: retreats $(\mathrm{R})$ corresponding to one of the contenders, during the 10-min confrontation (Formula 1). This index allows us to define the dominance condition of each member of the pair: the contender with the higher IDL is the winner (dominant) and the other the loser (subordinate). The second index is the dyadic dominance disparity (DDD\%), which involves measurements of both contenders and accounts for the disparity between them during the time they interact. It stands for the difference between the dominant and subordinate IDLs, over the total time both contenders spent performing agonist acts, multiplied by 100 (Formula 2). This index allows us to quantify the dyadic dominance disparity between opponents and therefore, an encounter was considered as defined if the DDD\% was higher than $20 \%$, if the criteria were not reached, the dyad was excluded from the analysis.

Formula 1: IDL $=\mathrm{AP}_{(\text {time })}+\mathrm{AT}_{\text {time) }}-\mathrm{R}_{\text {time) }}$

Formula 2: $\% \mathrm{DDD}=\left(\mathrm{IDL}_{\mathrm{Dom}}-\mathrm{IDL}_{\text {Sub }} /\right.$ Time agonist act $) \times 100$

Immediately after the agonistic phase, animals were transferred to individual containers and carried to the experimental room where the exploratory activity evaluation phase took place.

Exploratory activity evaluation phase Experimental device. Consisted of an opaque bowl-shaped container (12 $\mathrm{cm}$ high; $23 \mathrm{~cm}$ top diameter; $9 \mathrm{~cm}$ floor diameter) filled with artificial seawater to a depth of $0.5 \mathrm{~cm}$. The crabs could freely move inside the container but were not able to escape from it (Fig. 1a).

Exploratory activity evaluation. Once dominance condition was established, animals were placed in the container and five minutes of exploratory activity was videorecorded at $2 \mathrm{~Hz}$. Three days before the beginning of the experiment, each animal was marked with a little round piece $0.5 \mathrm{~cm}$ of yellow ethylene-vinyl acetate glued to the center of the carapace. Customized software was used to determine the $\mathrm{x}-\mathrm{y}$ coordinates of the yellow spot, which allowed us to track the animals and calculate the distance covered by the animal during exploration (Fig. 1c).
Experimental groups. Experiment 1 consisted of three groups: dominant animals (DOM), subordinate animals (SUB), and control animals (CT, animals that did not establish dominance condition). These animals serve as a baseline for the analysis of the exploratory activity response modulation due to confrontations. Experimental protocol (Fig. 2a).

\section{Experiment 2}

Effect of fight outcome on an aversive memory paradigm: fighting vs not fighting.

\section{Agonistic phase Same as experiment 1}

Memory phase: aversive memory paradigm Memory paradigm. The presentation of a visual danger stimulus (VDS; a black screen passing overhead) initially leads to an escape response that, after repeated presentations, is replaced by freezing (Pereyra et al. 1999). Fifteen presentations of the VDS, 3 min apart, induce an association between the iterated stimulus (unconditioned stimulus, US-VDS) and the contextual features of the container (conditioned stimulus, $\mathrm{CS}$ ). The memory is expressed as the context-specific longterm change of response to VDS, from escaping to freezing. Namely, the crab's response declines and is finally replaced by a strong freezing to VDS that constitutes the conditioned response (CR). The $\mathrm{CR}$ is here evaluated indirectly by assessing the reduction of the escape response.

Experimental device. The experimental device has been described in detail elsewhere (Fustiñana et al. 2013; Hepp et al. 2010; Maldonado 2002; Perez-Cuesta et al. 2007). Briefly, after confrontations, crabs were placed in the container, which was suspended from an upper wooden framework $(23 \times 23 \times 30 \mathrm{~cm})$ by three strings. A motor-operated screen (US, an opaque rectangular strip of $25.0 \times 7.5 \mathrm{~cm}$ ) was moved horizontally over the animal from left to right, and vice versa and represents the visual danger stimulus (VDS). The screen's movements were cyclical. The visual danger stimulus displacements provoked the escape response of the crab and subsequent container vibrations. Each trial lasted $9 \mathrm{~s}$ and consisted of two successive cycles of movement. Four microphones were attached to the center of the outside base of the container. The microphones recorded the vibrations that were produced by the animal's response. These signals were amplified, integrated during the entire trial (9s) and translated into arbitrary numerical units ranging from 0 to 8000 . During the experiment, the crabs were illuminated using a $5-\mathrm{W}$ bulb placed either above or below the container. A computer was employed to program the trial sequences, trial illumination, trial duration and intertrial intervals, and to monitor the experimental events. The 
A

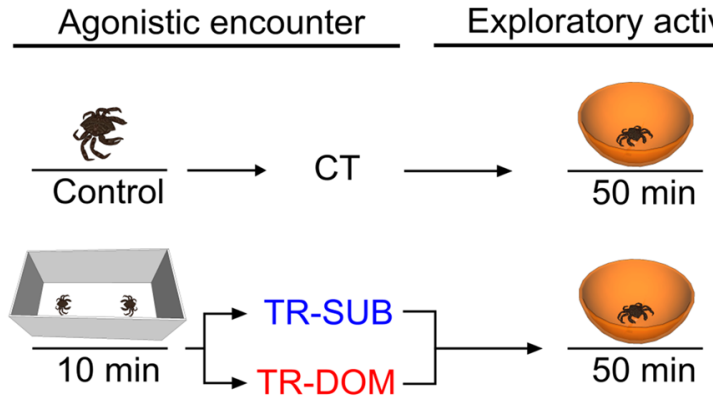

B

\section{Exploratory activity}

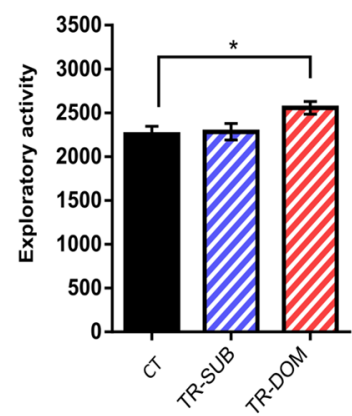

C

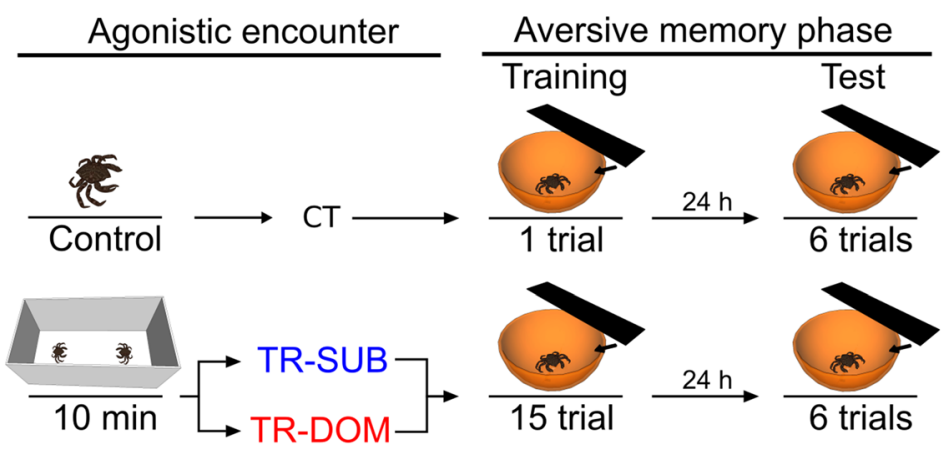

D

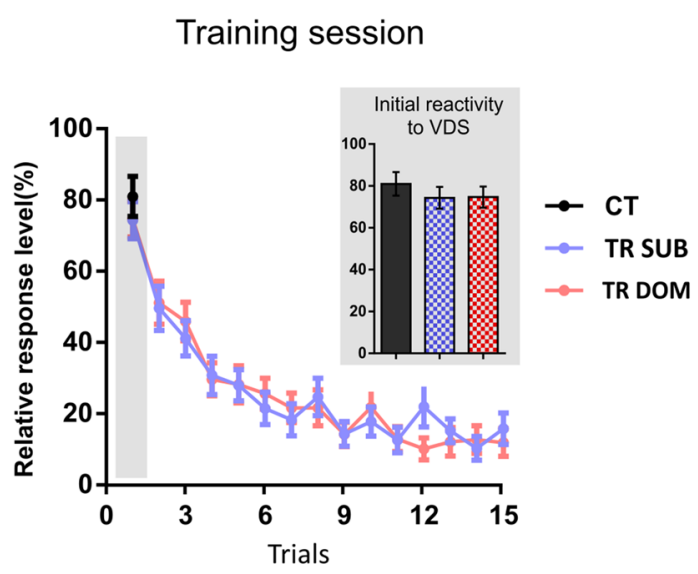

E

Test session

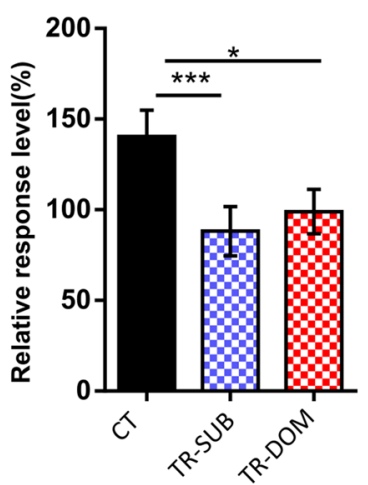

Fig. 2 Effect of fight outcome on exploratory activity, reactivity to VDS and aversive memory. a Experimental protocol: Agonistic encounter: A group of animals stablished dominance by confrontations (DOM/SUB) while another group did not fight and remained isolated (CT). The orange bowl-shaped container symbolizes the actometer. Exploratory activity was measured by video tracking. b Exploratory activity: immediately after fight, animals were placed in the actometers and exploratory activity was measured. c Experimental protocol: Agonistic encounter: A group of animals stablished dominance by confrontations (DOM/SUB) while another group did not fight and remained isolated (CT). The orange bowl-shaped container symbolizes the actometer. Black rectangles represent the
VDS and stands for aversive memory training and test. d Training session: immediately after fight the trained groups (TR DOM/TR SUB) received a training session of 15 VDS. The control group (CT) received 1 VDS and stayed in the context without stimulation. Training session shows mean animals response level along the 15 VDS trials. Inset: reactivity to the VDS, shows mean animals' response to the first presentation on the VDS in the training session. e Test session: took place after $24 \mathrm{~h}$, graph shows mean animals response level along the 6 VDS trials in the test session. Data are expressed as mean response level \pm S.E. Planned comparisons (LSD): *stands for $p<0.05$ (TR $<$ CT, memory retention). Group sizes: A, CT: 58, TRSUB: 58, TR-DOM: 59; B, CT: 32, TR-SUB: 31, TR-DOM: 33 
experimental room contained 40 experimental devices that were separated from each other by partitions.

Visual danger stimulus intensity. Distance between the individual container and the visual danger stimulus (VDS) was modified to study how parametric properties of the stimulus could influence the modulation of aversive memory acquisition and retention once dominance status was established. Thus, in the experiments, we used a standard stimulus intensity, that is, the distance between the container and the visual stimulus was $12 \mathrm{~cm}$, and a strong stimulus intensity where the distance was $6 \mathrm{~cm}$. Particularly, in this experiment (2), the standard stimulus intensity was used.

Aversive training session. Immediately after the agonistic encounter, the training session took place. It was preceded by $10 \mathrm{~min}$ of adaptation to the experimental device, which was illuminated from below. A strong contextual Pavlovian conditioning (CPC) training session consisted of 15 trials. A typical training trial lasted $27 \mathrm{~s}$ with above illumination (CS), and the visual danger stimulus (VDS) was presented during the last $9 \mathrm{~s}$. Thus, the VDS presentation coincided with the end of the CS presentation. The inter-trial interval (ITI) between VDS presentations was $171 \mathrm{~s}$, and the ITI between CS presentations was $144 \mathrm{~s}$. During the ITI between CSs, the experimental unit was illuminated from below, which provoked a virtual change in the environmental features (Fustiñana et al. 2013). All animals received one VDS presentation to evaluate the initial individual reactivity. Untrained animals (Control group) were kept in the experimental unit during the entire training procedure and were presented with the same pattern of light shift as trained animals, but without the visual danger stimulus (VDS) presentation (Fig. 1b). Immediately after the training session, crabs were moved from the experimental unit to individual resting containers until the test session, which were plastic boxes that were filled with water to a depth of $0.5 \mathrm{~cm}$. The resting containers were kept inside dimly lit drawers.

Aversive test session. All animals, trained and control groups, were tested $24 \mathrm{~h}$ after the training session. Crabs were transferred to the experimental device and after 10 min of adaptation which was initially illuminated from below, all animals received six trials of the visual danger stimulus (VDS) with the same temporal pattern and light shift described in the training session (Fig. 1b).

Memory aversive retention. Memory retention was defined as a statistically significant lower escape response level on the testing session by the trained (TR) group, relative to its respective untrained/control (CT) group.

Experimental groups. Experiment 1 consisted of three groups: Control animals (CT, animals that did not establish dominance condition) were assigned to the untrained group (CT) of the mnesic phase, that is, received one reinforced visual danger stimulus (VDS) trial and remained in the training context subject to the lighting shift. On the other hand, both contenders of each dyad, dominant and subordinate, were assigned to the trained group (TR) of the mnesic phase. Thus, the experiment consisted of three groups: CT, TRDOM and TR-SUB. Experimental protocol (Fig. 2c).

\section{Experiment 3 and experiment 4}

Effect of fight outcome on an aversive memory paradigm: changing the parametric properties of the visual danger stimulus (VDS).

Agonistic phase Same as Experiment 1. With the exception that no control group (animals that did not fight) was performed.

Memory phase: aversive memory paradigm Same as Experiment 2. Two independent experiments were performed to analyze the effect of increasing the intensity of the visual danger stimulus on aversive memory modulation by fight outcome. Thus, both experiments share the same experimental groups but differ in the training session of the memory phase. In one experiment (3), animals were trained with the standard intensity stimulus and in the other experiment (4), animals were trained with the strong stimulus intensity (Table 2).

Experimental groups. Experiments 3 and 4 consisted of four groups (Table 2): immediately after the agonistic phase, each animal was moved from individual container to one experimental device. Both contenders of each dyad were

Table 2 Experimental groups

\begin{tabular}{lllll}
\hline & Agonistic phase & Memory phase & & \\
\hline Experiment & Agonistic encounter & Experimental group & VDS presentation & \\
3 (Standard & & & Training & Test \\
VDS) & & CTSUB/DOM & 1 VDS & 6 VDS \\
& & TRSUB/DOM & 15 VDS & 6 VDS \\
Experiment 4 & \multirow{2}{*}{ Agonistic encounter } & Experimental group & VDS presentation & \\
(Strong VDS) & & & Training & Test \\
& & CTSUB/DOM & 1 VDS & 6 VDS \\
& & TRSUB/DOM & 15 VDS & 6 VDS \\
\hline
\end{tabular}


assigned to the same training protocol. That is, the dominant and its respective subordinate were assigned to the control group of the mnesic phase or the trained group. Thus, the experiment consisted, of four groups: CT-DOM, CT-SUB TR-DOM and TR-SUB. Experimental protocol (Fig. 3a).

\section{Experiment 5}

Effect of social isolation on an aversive memory paradigm.

Social isolation phase One day after laboratory arrival, 80 animals were isolated in individual opaque containers (12 cm diameter, $15 \mathrm{~cm}$ height), filled to $0.5-\mathrm{cm}$ depth with diluted marine water and without food, for at least 6 days before the initiation of the mnesic phase (Isolated group).
Simultaneously, 80 animals remained grouped in plastic tanks $(35 \times 48 \times 27 \mathrm{~cm})$ for the same time period as the isolated, filled to $0.5-\mathrm{cm}$ depth with marine water and without food, to a density of 20 crabs per tank (Grouped group).

Memory phase: aversive memory paradigm Same as Experiment 2. Experimental groups. Isolation group and grouped animals were assigned to the same training protocol. That is, to the control group of the mnesic phase or to the trained group. Thus, the experiment consisted of four groups: CT-Isolated, CT-Grouped, TR-Isolated and TRGrouped. Experimental protocol (Fig. 4a).
Fig. 3 Effect of fight outcome on reactivity to VDS and aversive memory: an analysis of the parametric properties of the stimulus (VDS). a Experimental protocol: Agonistic encounter: animals stablished dominance by confrontations (DOM/ SUB). Symbols as Fig. 1a. b-d Training session: immediately after fight the trained groups (TR-DOM/TR-SUB) received a training session of 15 VDS with standard stimulus (b) or strong stimulus (d). The control group (CT-SUB/CT-DOM) received 1 VDS and stayed in the context without stimulation. Training session shows mean response level along the 15 VDS trials. Inset: reactivity to the VDS, shows mean response to the first presentation on the VDS in the training session. c-e Test session: took place after $24 \mathrm{~h}$, graph shows mean response level along the 6 VDS trials in the test session with the standard stimulus (c) or higher stimulus (e). Data are expressed as mean response level \pm S.E. Planned comparisons (LSD): *stands for $p<0.05$ (TR $<\mathrm{CT}$, memory retention). Group sizes: B-C, CT-SUB: 34, TR-SUB: 31 , CT-DOM: 40, TR-DOM: 34 : D-E, CT-SUB: 22, TR-SUB: 22, CT-DOM: 23, TR-DOM: 22

A

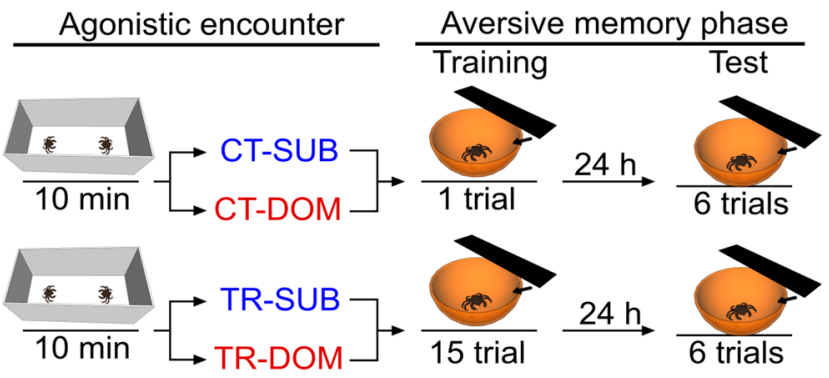

\section{B}

Training session (standard VDS)

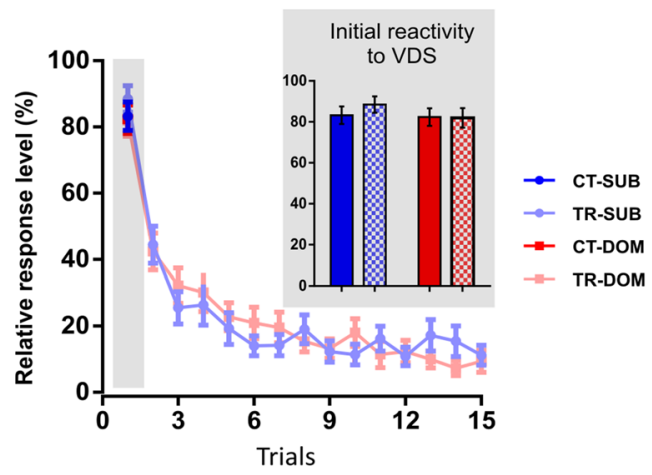

D

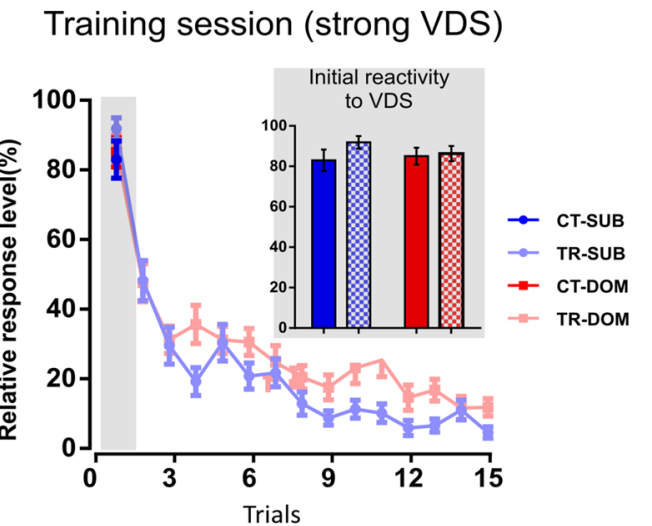

C Test session (standard VDS)

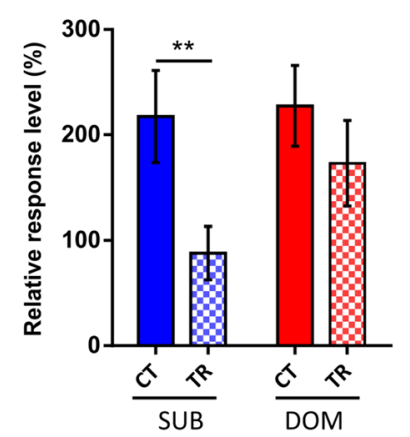

$\mathbf{E}$

Test session (strong VDS)

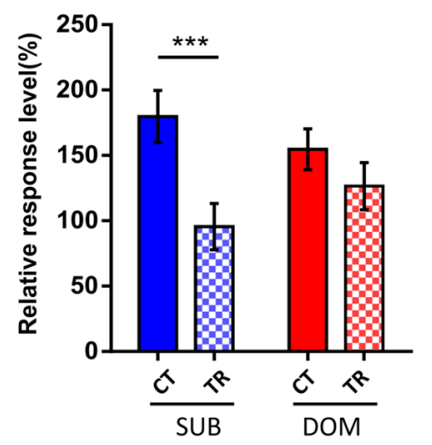


Fig. 4 Effect of social isolation in the acquisition and retention of an aversive memory. a Experimental protocol: Two pairs of control (CT) - trained (TR) groups: animals that spend a week in isolation in individual containers and animals that remained grouped with 20 crabs per container. Symbols as Fig. 1a. b Training session: after 1 week the trained groups (TRGROUPED/TR-ISOLATED) received a training session of 15 VDS. Control groups (CTGROUPED/CT-ISOLATED) received 1 VDS and stayed in the context without stimulation. Training session shows mean response level along the 15 VDS trials. Inset: reactivity to the VDS, shows mean response to the first presentation on the VDS in the training session. $c$ Test session: took place after $24 \mathrm{~h}$, graph shows mean animals response level along the 6 VDS trials in the test session. Data are expressed as mean response level \pm S.E. Planned comparisons (LSD): *stands for $p<0.05$ ( TR $<\mathrm{CT}$, memory retention). Group sizes: CT-GROUPED: 31, TR-GROUPED: 32, CT-ISOLATED: 31, TR-ISOLATED: 32
A

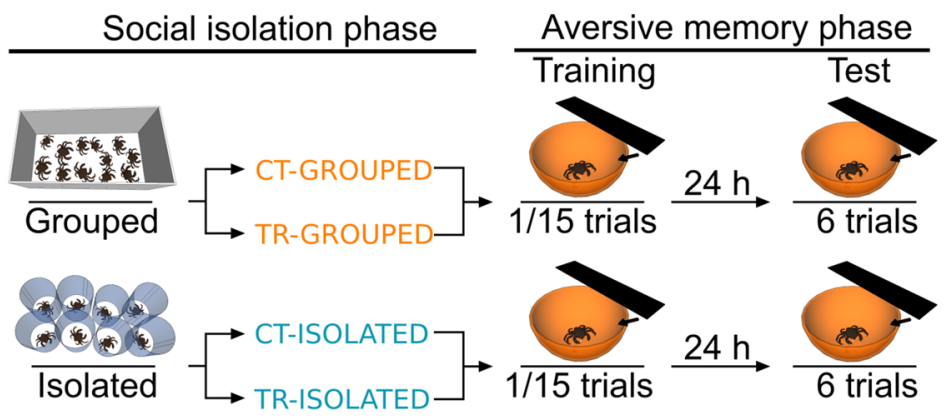

B

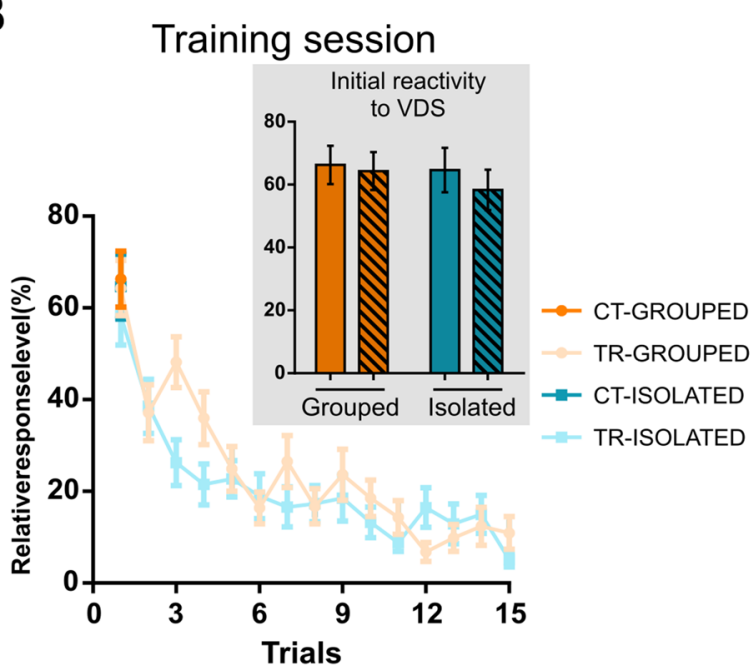

C

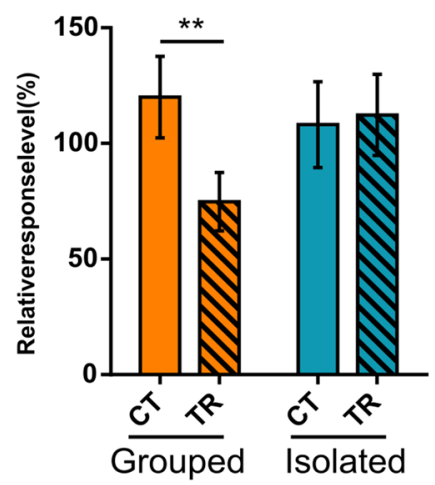

\section{Experiment 6}

Effect of fight outcome on an appetitive memory paradigm.

Agonistic phase. As experiment 1 Memory phase: appetitive memory paradigm Memory paradigm. The appetitive memory paradigm is based on an animal's association between a training context and a positive reward (food pellet). When a group of crabs has received food in the training context, a contextual appetitive memory is disclosed 1 or $2 \mathrm{~d}$ later given by a decrease in exploratory activity when compared to a control group that did not receive the food pellet (Kaczer and Maldonado 2009; Klappenbach et al. 2012). Such increment in exploratory activity between groups is interpreted as an increase in the pursuit of the positive reinforcement previously received in the context.

Experimental device. The same experimental device described in the exploratory activity section was used.

Appetitive training session. Immediately after the establishment of dominance condition, crabs were individually placed in the training context. After 5 min of adaptation, one group of animals defined as the trained group (TR) received a specific amount of food in the form of one rabbit pellet (Nutrientes Argentina SA). Normally, crabs explore the container until it finds the food pellet and starts eating until the pellet is finished. Food quantity (pellet weight) in the trained group was $80 \mathrm{mg}$. After $45 \mathrm{~min}$, crabs were removed from the training context and placed individually in boxes until the next session. Another group of animals defined as the control group (CT, untrained) remained in the training context without food during the 50 min that lasted the whole training session. Immediately after the training session, crabs were moved from the experimental unit to individual resting containers until the test session (Fig. 1c).

Appetitive test session. Twenty-four hours after training, all crabs were placed in the experimental device and exploratory activity was measured for $5 \mathrm{~min}$ (Fig. 1c). Animal's activity was video-recorded at $2 \mathrm{~Hz}$ and analyzed by 
video-tracking as specified in the exploratory activity section above.

Appetitive memory retention. Memory retention was defined as a statistically significant increase in the exploratory activity level on the testing session by the trained (TR) group, relative to its respective untrained/control (CT) group.

Experimental groups. Dominant and its respective subordinate were assigned to the control group (no food pellet received) of the appetitive mnesic phase or to the trained group (food pellet administration). Thus, the experiment consisted, of four groups: CT-DOM, CT-SUB TR-DOM and TR-SUB. Experimental protocol (Fig. 5a).

\section{Statistical analysis}

Memory retention: Long-term memory retention is operationally defined as a significant difference between the CT and TR groups in the mean response level during the evaluation session, such that $\mathrm{TR}<\mathrm{CT}$ in aversive memory paradigm or TR $>$ CT in appetitive memory paradigm. In other words, the analysis of the data is focused on the response levels during the testing session. We use this type of analysis instead of training $v s$. testing due to the fact that it allows distinguishing between the time of information acquisition and the time of its evaluation (Rescorla 1988), under the conception that the behavior of the animal can differ between the two sessions for reasons not related to learning and in this way accentuate or overshadow differences typical of the memory phenomenon. Based on a large number
Fig. 5 Fight outcome and modulation of an appetitive memory. a Experimental protocol: Agonistic encounter: animals stablished dominance by confrontations (DOM/SUB). Symbols as Fig. 1a. b Test session: immediately after fight the trained groups (TR-DOM/ TR-SUB) received a food pellet. The control group (CT-SUB/ CT-DOM) stayed in the context without stimulation. After $24 \mathrm{~h}$ animals were tested measuring exploratory activity by video tracking. Graph shows mean exploratory activity level at test session. Data are expressed as mean response level \pm S.E. Planned comparisons (LSD): *stands for $p<0.05$ (TR $>$ CT, memory retention). Group sizes: CT-SUB: 29, TR-SUB: 32, CTDOM: 28, TR-DOM: 29
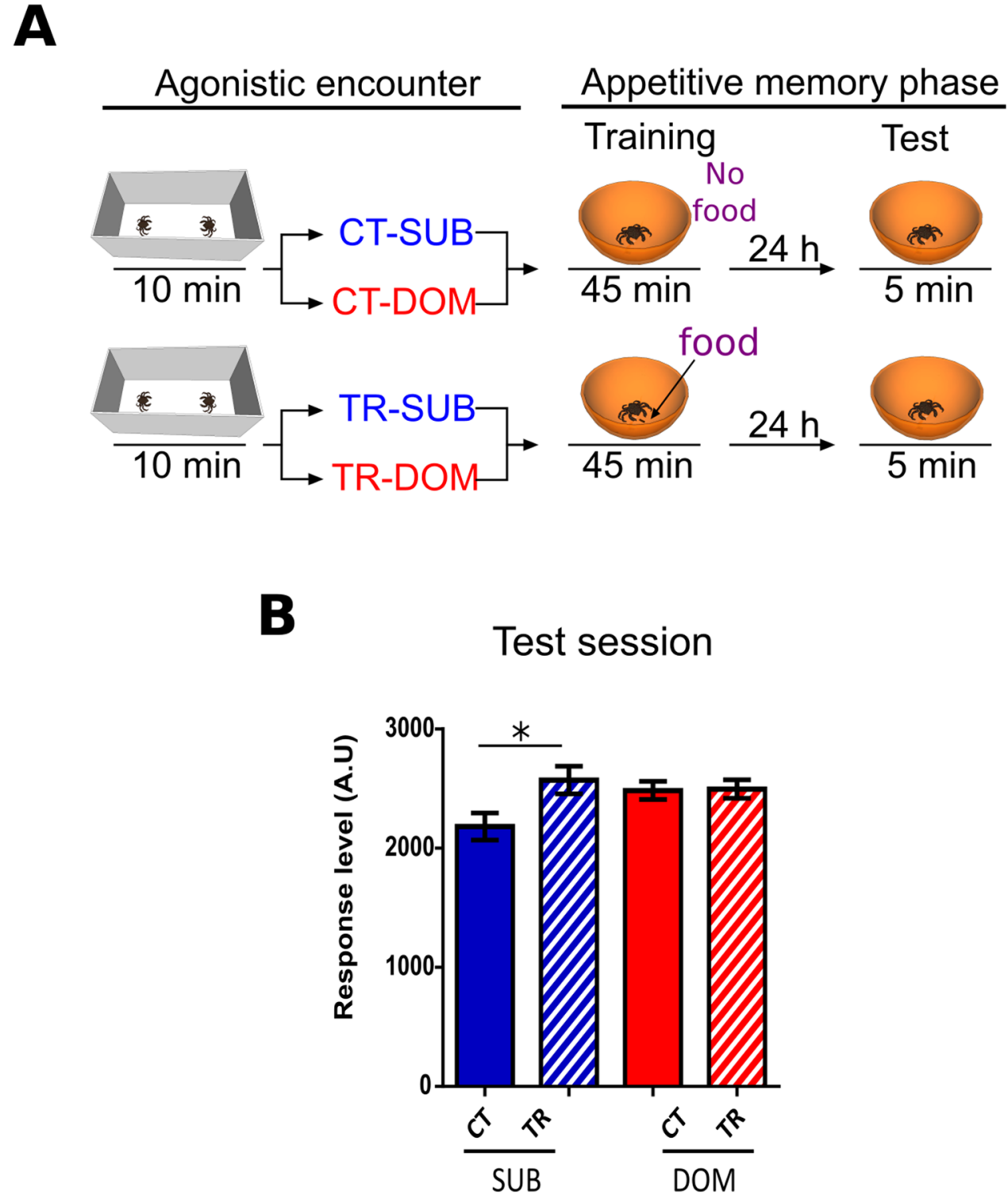
of experiments carried out with these learning paradigms, a basic prediction is established: in all cases, there will be a significant difference between the CT and TR groups in the evaluation session. For this reason, the statistic of a priori planned comparisons is used (Howell 1987; Rosenthal and Rosnow 1985) contrasts: 1) a contrast between the untrained groups (CTs), whose answers are expected to be similar, 2) a contrast by each untrained group (CT) and its respective trained group (TR). These comparisons are made after a oneway ANOVA presented significant differences $(p<0.05)$.

Learning phase: Data from the training session in the aversive memory paradigm were evaluated using a repeated measures ANOVA test (factor: TR DOM/SUB, repeated measure: trials).

On the other hand, we used a correlation analysis using the Pearson coefficient, between the individual dominance level (IDL) and the response to the first visual danger stimulus (VDS) presentation.

\section{Data analysis}

Sample size and selection criteria. All the experiments carried out in this work started with 40 animals per experimental group, except for experiments 1 and 3 that started with 80 (Supplementary_Table 1). However, the final number of animals per group reached between 22 and 59 ( $\mathrm{N}$ of each group is specified in figures legends and Supplementary_Table 1). This variability in terms of sample size was due, on the one hand, to the fact that during the agonistic phase, there was a percentage of undefined fights, that consequently, were not included in the subsequent analysis. On the other hand, regarding the aversive memory phase, an animal elimination criterion was applied to take into account the response to the first passage of the visual danger stimulus in the training session. In this sense, animals with escape responses or exploratory activity 2 or more standard deviations away from the group mean were considered outliers and excluded from the analysis. Further, in experiments in which animals of the experimental control group did not undergo the agonistic phase (Experiments 1 and 2), a few animals were randomly eliminated to balance the final $\mathrm{N}$ across groups.

Data normalization. In general, work with animal models deals with the associated biological variability by standardizing behavioral responses and environmental conditions (Laukens et al. 2016; Voelkl et al. 2020; Willmann et al. 2012; Beynen et al. 2003). Here, in the aversive memory paradigm, the escape response during each trial was normalized against each animal's maximum escape response (considered as 100\%). As memory retention, we presented the mean response along the six test trials presented in the test session. Therefore, values presented at the test session are the mean of those normalized values leaving the response of the animals always measured in the same range (from 0 to $>100 \%$ ) and expressed as percentage mean value \pm percentage standard error. This normalization allows, on the one hand, to contrast changes in the response of animals in the same experiment, to evaluate memory in experimental groups that have a reduced size and it also allows comparisons to be made between different experiments regardless of the general response level of the population (Hepp et al. 2016).

Data were analyzed using the Statistica 8 program (Windows 7; software package 3; StatSoft Inc., Tulsa).

\section{Results}

\section{Effect of fight outcome and social isolation in the acquisition and retention of aversive memory}

\author{
The relationship between an agonistic encounter, \\ exploratory activity and the response to a visual danger \\ stimulus (VDS): fighting versus not fighting. Experiment 1 \\ and 2
}

Once the dominance condition was established, in the first instance, we aimed to study the effect of an agonistic encounter in two different behavioral outcomes: exploratory activity and the reactivity to a visual danger stimulus. To address this, we compared dominant and subordinate animal responses in contrast to a group of animals that did not fight (control, CT) and therefore served as a baseline for the analysis of the response modulation.

Exploratory activity. Immediately after the agonistic phase, exploratory activity was measured. (Experimental protocol, Fig. 2a). Significant differences were only found between dominant and control animals [ANOVA: $F_{2,172}=3.742, p=0.02$; planned comparisons: CT vs. TRDOM: $p=0.03$; CT vs. TR-SUB: $p=0.99$; TR-DOM vs. TRSUB: $p=0.06]$. Therefore, this result revealed an increase in exploratory activity for dominant when compared with those that did not establish a dominance condition (Fig. 2b). In line with this, a positive correlation was found between the individual dominance level and the exploratory activity $[r=0.2251, p=0.01, N=87]$ (Supplementary Fig. 1a).

Reactivity to visual danger stimulus (VDS). Immediately after the fight, the aversive mnesic phase took place. To evaluate potential differences in escape response to the VDS as a consequence of dominance status, the responsiveness of each animal to the first VDS presentation at the training session was analyzed. (Experimental protocol, Fig. 2c).

The initial reactivity to the visual danger stimulus (Fig. 2d) revealed no significant differences between groups [ANOVA: $F_{2,88}=0.68, p=0.50$ ]. That is, dominant, subordinate and control animals have a similar response level to 
the first presentation of the stimulus. A correlation between the individual dominance level and the response to the first passage of the visual danger stimulus revealed no significant differences [ $r=0.1985, p=0.13, N=59$ ] (Supplementary Fig. 1b). Altogether, these results suggest that the fight outcome does not seem to influence the reactivity of the animals towards an aversive stimulus.

\section{Acquisition and retention of an aversive memory after the establishment of dominance condition: fighting versus not fighting. Experiment 2}

Previous results (Kaczer et al. 2007), showed that subordinate crabs have greater memory retention than the dominant $72 \mathrm{~h}$ after the confrontations in an aversive memory task. Here, we investigate whether this modulation persists even though the time window between the agonistic phase and the memory phase was shortened. Thus, we analyzed the shortterm effects of dominance status not only regarding differences in memory retention but also considering whether this modulation came from differences in memory acquisition.

Learning rate. When evaluating the response of the animals throughout the 15 training trials in the training curve (Fig. 2d), no significant differences between dominant and subordinate-trained groups were found [repeated measures ANOVA: $\left.F_{1,59}=0.68, p=0.77\right]$. Thus, the dominance condition did not modulate the acquisition rate of aversive memory.

Aversive memory retention. As we previously described, memory retention is operatively defined based on a decrease in the escape response of trained animals with respect to control animals (CT > TR) on the day of the evaluation. Based on this prediction, we compare the response of dominant and subordinate-trained animals to control animals in the block of the six evaluation trials. Significant differences were found for both dominant and subordinate-trained groups when compared to the control group (CT $>$ TR-DOM/SUB) [ANOVA: $F_{2,91}=4.103, p=0.02$; planned comparisons: [CT vs. TR-DOM: $p=0.04$; CT vs. TR-SUB: $p=0.008]$. That is, both dominant and subordinate animals show long-term memory retention (Fig. 2e).

A positive significant correlation between the individual dominance level and the response to the first trial at test session was found $[r=0.3534, p=0.001, N=59]$ (Supplementary Fig. 1c). That is, a higher dominance level entails a higher response level which implies lower memory retention.

However, it becomes necessary to compare dominant and subordinate-trained groups with their respective controls, that is, animals that go through the agonist phase and receive a single stimulus during the training session. In the next series of experiments, such control groups were considered in the design.
Direct effect of fight outcome on aversive memory acquisition and retention: an analysis of the parametric properties of the visual danger stimulus (VDS). Experiment 3 and 4

TTo evaluates in depth the potential effect of dominance condition in an aversive memory, in the next series of experiments, we evaluated animal's performance with two different stimuli (VDS) intensities: a standard and a stronger one.

Taking into account both agonist and memory phases, the following groups were formed: TR-DOM, TR-SUB, CTDOM, CT-SUB (Fig. 3a). This design allows us to evaluate memory retention in terms of the comparison of dominant and subordinate-trained animals with respect to animals that were not trained, but that established the dominance condition. In this way, unlike the previous experiment, we compared the response of animals that started from the same conditions and therefore studied whether an agonistic encounter that occurs $24 \mathrm{~h}$ before was able to modulate a long-term memory.

An analysis of the response to the first screen passage (VDS) in the training session revealed no significant differences between groups (Fig. 3b) [ANOVA Standard VDS: $\left.F_{3,66}=0.44, p=0.72\right]$. Likewise, despite increasing the salience of the stimulus, no significant differences were observed between dominant and subordinates in terms of

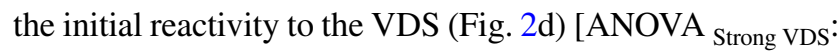
$\left.F_{3,10}=1.23, p=0.29\right]$.

Consistent with these results, the correlation analysis did not reached significance for both stimuli intensities $[r$ Standard VDS $=-0.0844, p=0.25, \mathrm{~N}=67$ ] (Supplementary Fig. 2a; $\left[r_{\text {Strong vDS }}=-0.0941, p=0.29, N=42\right]$ (Supplementary Fig. 2c).

No significant differences were observed between dominant and subordinate-trained throughout the 15 trials for both type of stimuli [ANOVA Standard VDS repeated measures: $F_{14,40}=1.00, p=0.44$ ]; [ANOVA ${ }_{\text {Strong VDS }}$ repeated measures: $F_{14,58}=1.31, p=0.61$ ] (Fig. $3 b, \mathrm{~d}$ ).

The analysis of the 6 trial block revealed significant differences between the subordinate control and trained groups (CT-SUB $>$ TR-SUB) while no differences were found between the dominant control-trained groups (CTDOM TR-DOM) and between dominant and subordinate-

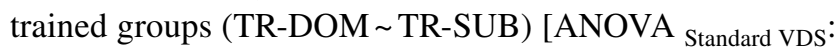
$F_{3,66}=2.53, p=0.02$; planned comparisons: CT-SUB vs. TR-SUB: $p=0.01$; CT-DOM vs. TR-DOM: $p=0.22$; TRDOM vs. TR-SUB: $p=0.13$ ]. That is, only subordinates showed memory retention (Fig. 3c). Moreover, we analyzed if the modulatory effect, previously observed, persisted even though the presentation of a stimulus of greater intensity, or on the contrary, a stronger stimulus was able to dispel these differences. Again, significant differences were observed 
between the subordinate groups (CT-SUB $>$ TR-SUB) while the dominant groups did not reveal any differences (CT-DOM TR-DOM). No differences were found between dominant and subordinate-trained groups (TR-DOM $\sim$ TRSUB) [ANOVA Strong VDS: $F_{3.04}=1.79, p=0.02$; planned comparisons: CT-SUB vs. TR-SUB: $p=0.004$; CT-DOM vs. TR-DOM: $p=0.33$; TR-DOM vs. TR-SUB: $p=0.29$ ] (Fig. 3e).

A significant correlation was found when evaluating the response to the first VDS at test session $[r$ Standard VDS $=0.2032, p=0.04, N=67$ ] (Supplementary Fig. 2b) with the standard stimulus but no significant correlation was found with the VDS higher intensity $[r$ Strong VDS $=-0.1448, p=0.19, N=42$ ] (Supplementary Fig.2d).

Altogether, these results indicate that the dominance condition has a differential effect on memory retention and that the effect persists even increasing the intensity of the stimulus.

\section{Social isolation has a detrimental effect on aversive memory retention. Experiment 5}

Taking into account that previous experiments included an isolation period before the confrontation, this experiment aimed to evaluate the effect of social isolation in the reactivity to the visual danger stimulus, the acquisition and the retention of an associative aversive memory.

This experiment consisted of two pairs of control (CT) trained (TR) groups: CT isolated, $\mathrm{TR}_{\text {isolated, }} \mathrm{CT}$ grouped $\mathrm{TR}$ grouped. (Experimental protocol, Fig. 4a).

Escape response to the first screen passage (VDS) during the training session revealed no significant differences between groups [ANOVA: $F_{3,139}=1.776, p=0.154$ ] (Fig. 4b). Hence, social isolation did not affect animal's reactivity to a visual danger stimulus.

Analysis of the training curve revealed no significant differences between isolated and grouped animals throughout the 15 training trials [ANOVA repeated measures: $\left.F_{14,40}=1.00, p=0.44\right]$ (Fig. 4b). Therefore, the absence of social interactions did not modify aversive memory acquisition.

In terms of memory retention, significant differences were observed between the control and trained groups of grouped animals $\left(\mathrm{CT}_{\text {grouped }}>\mathrm{TR}_{\text {grouped }}\right)$, showing long-term memory retention, while isolated animals did not reveal any differences ( $\mathrm{CT}_{\text {isolated }} \sim \mathrm{TR}$ isolated ) [ANOVA: $F_{3,137}=2.96$, $p=0.03$; planned comparisons: CT grouped vs. TR grouped: $p=0.015 ; \mathrm{CT}_{\text {isolated }}$ vs. TR isolated: $p=0.58$ ] (Fig. 4c).

This result indicates that isolation conditions have a detrimental effect on aversive memory retention.

\section{Fight outcome also modulates memory retention in an appetitive paradigm. Experiment 6}

Until now, we explored so far, the effect of agonistic encounters on an aversive memory. In natural settings, agonistic encounters are not exclusively related to aversive learnings. Thus, to enrich the scenario, the next experiment was aimed to study the modulatory effect of a fight on an appetitive memory. Differently from the aversive paradigm, a trained group (TR) is said to show memory when its mean exploratory activity is significantly greater than the untrained/control group $(\mathrm{CT})$. $(\mathrm{CT}<\mathrm{TR})$.

Immediately after the agonistic phase, the appetitive mnesic phase took place. Thus, the following groups were formed: TR-DOM, TR-SUB, CT-DOM, CT-SUB. (Experimental protocol Fig. 5a).

Results of the test session analysis revealed significant differences between the subordinate control and trained groups (CT-SUB $<$ TR-SUB) while no differences were found between dominant (CT-DOM TR-DOM) [ANOVA: $F_{3,114}=3.030, p=0.03$; planned comparisons: CT-SUB vs. TR-SUB: $p=0.005$; CT-DOM vs. TR-DOM: $p=0.93$ ] (Fig. 5b). That is, only subordinates showed appetitive memory retention. No significant correlation was found between response level and individual dominance level (IDL) when tested $24 \mathrm{~h}$ after fight $[r=0.065, p=0.31, N=62]$ (Supplementary Fig. 3).

Thus, these results suggest a differential modulation of appetitive memory retention: winning a fight results in a detrimental effect while losing is reflected by an appetitive memory improvement.

\section{Discussion}

The present work investigated how different social contexts could shape the acquisition, consolidation, and retention of associative memories. Particularly, we assessed the shortterm effects of fight outcome in an aversive memory paradigm extending the analysis to how the result of an agonistic encounter could modulate not only memory retention but also the exploratory activity and the reactivity to a visual danger stimulus, behaviors that could affect animal's performance in cognitive tasks. Further, we found enriching to evaluate how social isolation could modulate an aversive memory and how dominance could affect performance in an appetitive memory paradigm. 


\section{Effect of fight outcome in the reactivity to a visual danger stimulus (VDS) and exploratory behavior in the crab Neohelice granulata}

Our first aim was to study the effect of dominance status on the escape response elicited by a visual danger stimulus. In particular, we were interested in evaluating whether the reactivity to the stimulus could be modulated immediately after the establishment of a dominance condition. Briefly, the results showed that dominant and subordinate animals did not differ in the response to the first presentation of the visual danger stimulus (even using a high stimulus salience) and that their reactivity was not different from animals that did not establish a dominance status (Figs. $2 d$ and 3b, d). Indeed, we did not find a correlation between the individual dominance level and the response to the first passage of the stimulus (Supplementary Fig. 1b).

These results seem to contradict the hypothesis in which we expected a differential response from the animals to the VDS as a consequence of a confrontation. Based on results in other crustacean species, it was expected that the subordinates present a greater reactivity than the dominant ones. In crayfish, the animal's reactivity in a mirror test was analyzed after a confrontation (Brudzynski et al. 2006; May and Mercier 2007). Dominant animals tended to get closer to the image while the subordinate animals tended to evoke escape responses. Further, with a tactile stimulus, dominants were found to evoke an orientation response towards the stimulus while subordinates tended to escape from it (Song et al. 2006). Thus, it is worth considering that a tactile stimulus could be perceived as a conspecific's attack, then, a subordinate animal tends to escape while a dominant animal tends to confront it. Contrastingly, in our work, the visual danger stimulus is presented above the crab's visual horizon and perceived by the animal as potentially dangerous, since its main predator is the seagull. In this way, the stimulus would not represent an attack from conspecific, which may or may not imply a risk, but might denote a potential predator. Thus, maintaining the escape response independent from the dominance condition could result in an advantage for an animal's survival.

Analysis of exploratory behavior revealed that dominant animals have a higher exploratory activity when compared to individuals that did not establish a dominance condition (Fig. 2b). This result adds evidence to several works in different species that have analyzed how the social environment can modify different behaviors including exploratory activity (Dingemanse and Goede 2004; Drea 1998; Drent et al. 1996; Francia and Cirulli 2006; Moyers et al. 2018). Differences in exploratory activity have been extensively discussed and interpreted among personality differences framework. In birds, for example, it has been found that fast-exploring birds had higher dominance ranks than low-exploring individuals although the opposite effect was observed with non-territorial males (Dingemanse and Goede 2004). Thus, a personality trait, such as exploratory activity, varies according to territorial status, being highly associated with dominance rank. In female zebra finches, social dominance was predicted by personality: proactive individuals were more likely to be dominant (David et al. 2011). Hence, it is worth discussing what comes first: dominance determines certain personality traits or can pre-established individual differences determine dominance rank? In this sense, it is likely that this effect cannot be differentiated as such parameters may covariate. Nonetheless in our work, exploratory activity was measured after confrontations, therefore, results are interpreted as the consequence of winning or losing a fight and no differences have been measured before the establishment of dominance condition.

All in all, in social groups, where dominant relationships are established, individuals with higher status have prioritized access to resources (Popp and DeVore 1979; Wilson 1975). In this way, it could be argued that this differential modulation might reflect the difference between dominant and subordinate in terms of the exploitation of resources that are limited in nature.

\section{Differential modulation of an aversive and an appetitive memory by fight outcome}

Kaczer and colleagues (2007) had shown that a context-signal memory was modulated by a fight encounter staged $48 \mathrm{~h}$ before learning in Neohelice granulata. Hence, our goal was to investigate whether this modulation is also found even though the time window between the agonistic phase and the memory phase was shortened. To reach such goal, we focused the analysis on the immediate effect of the dominance condition on the acquisition and retention of aversive memory. First, we observed that performance in the learning task was not differentially affected by the dominance condition (Figs. 2d.and 3b, d). Second, regarding the effect of the dominance condition on memory retention, we find an inverse relationship between the individual dominance level and the response to the stimulus at testing. That is, the higher the dominance level, the less retention was expressed (Supplementary Figs.1c and 2b). Only subordinates showed memory retention (Figs. 2e. and 3c, e). These results gain relevance as they replicated and expand those obtained previously (Kaczer et al. 2007). Replicability crisis is being in the center of discussion among several research fields (Loken and Gelman 2017) thus. Despite the different experimental conditions (i.e., the time window between the agonistic and memory phases), we found the same modulatory effect. Therefore, the maintenance of this modulation gives strength to this behavioral manipulation. 
Going a step forward, we also evaluated how the fight outcome might modulate an appetitive memory in the crab Neohelice granulata. As in the aversive paradigm, results showed memory retention in subordinates but not in dominant (Fig. 5b). Here, memory retention is given by an increase in the exploratory activity of trained animals. On the other hand, the basal exploratory activity was found to be greater in dominant in contrast to those that did not fight (Fig. 2b). These results could indicate that there is an effect on the intrinsic conditions of animals after a fight. Thus, the impact of the fight outcome on memory modulation would be independent of those initial differences.

To our knowledge, few reports have compared the effect of dominance in different cognitive tasks. In a work carried out in birds, Arabian babblers (Turdoides squamiceps), Keynan and co-workers suggested that differences in learning between dominant and subordinates might be task-specific revealing differences in cognitive strategies (Keynan et al. 2015, 2016). First, birds learned to remove black rubber lids from a foraging grid. Then, to evaluate how quickly subordinates and dominants learn a slightly different task, newly white rubber lids that they have never seen before were included. Hence, although the task is different, it does not entail a significant change in the type of learning, and does not involve survival strategies, like the ones we addressed in our study. Our results provide evidence and enrich the study of the dominance condition as a general memory modulator leading to the hypothesis that fight outcome could modulate in the same way different general cognitive tasks.

It has been extensively studied that cognitive abilities require energy. Although cognitive functions, such as learning and memory, have been mostly discussed in terms of their benefits, they also imply energetic cost (Ames 2000; Dukas 1999; Jaumann et al. 2013; Laughlin et al. 1998). The energetic cost can lead to impairments or trades-off when the amount of available energy is limited (Mery and Kawecki 2005; Pravosudov et al. 2005; Snell-Rood et al. 2011). In social animals, however, the negative effects of energetic stress on the cognitive ability of an individual can potentially be mitigated by changes in resource allocation patterns at the group level (Jaumann et al. 2013). This might be useful in social cooperative groups but might have other impacts when interactions result in competition. In this scenario, it worth asking what might be the cost of fighting in cognitive performance. A recent study in mice analyzed the effect of agonistic in an aversive memory paradigm (inhibitory avoidance) (Monlen et al. 2015). After 5 min of confrontations, subordinate animals showed an increase in memory retention. On the other hand, when the duration of the confrontations was $10 \mathrm{~min}$, a deleterious effect on memory was observed. The authors propose an explanation for these results in terms of the stress produced as a consequence of social defeat. In our case, the degree of aggressiveness during confrontations is not high, although we cannot rule out the possible influence of stress as a product of social interaction on memory modulation. In lobsters, heart rate was analyzed before, during, and after an agonistic encounter (Hernández-Falcón et al. 2005). The authors found a correlation between heart rate and fight outcome. That is, winners, evidenced an increase in heart rate compared to the subordinates, remaining elevated for at least $15 \mathrm{~min}$ after the end of the fight. Recent data also suggest that the heart rate in the Neohelice granulata crab increases during agonistic interactions (Canero and Hermitte 2014); therefore, this parameter could serve to study a correlation between stress levels after a fight and the consequences that this might have on the modulation of memory retention.

\section{When social context change: effect of social isolation in an aversive memory paradigm}

The effects of social isolation in behavior and cognition have been extensively studied mainly in vertebrates (Blanchard et al. 2001; Cacioppo and Hawkley 2009; Gluck and Harlow 1971; Lopez et al. 2011; Makinodan et al. 2016; Medendorp et al. 2018; Shams et al. 2015). However, less is known about the effects in invertebrate models. As social environment not only involves interactions with conspecifics but also, in some circumstances, animals might deal with social isolation, we aimed to study how social context could influence performance in learning and memory. Thus, we evaluated the effect of social isolation in an aversive memory paradigm. After one week of isolation, animals showed no memory retention when compared with animals that remained grouped for the same period time (Fig. 4c). Therefore, isolation conditions have a detrimental effect on aversive memory retention. This result is consistent with several works that associate social isolation with cognitive impairments, such as recognition memory deficits, conditioned fear memory deficits, and object location memory deficits (Green and McCormick 2013; McIntosh et al. 2013; Okada et al. 2014) as well as spatial memory deficiency (Wang et al. 2019). Moreover, in Drosophila melanogaster and Apis Mellifera, isolation resulted in a reduction of fiber density and mushroom bodies volume, structures associated with learning and memory processing (Maleszka et al. 2009; Technau 2007). Likewise, in the pond snail Lymnaea stagnalis, it was showed that environmental context alters the effect of isolation on long-term memory formation (Dalesman and Lukowiak 2011). Further, our result becomes relevant in the current social isolation context due to COVID-19, where several recent studies revealed negative consequences of isolation on mental and physical health (Manca et al. 2020; Plagg et al. 2020; Sepúlveda-Loyola et al. 2020). Altogether, the present work sums evidence in the analogous effects of 
social isolation on learning and memory processes, principally investigated in vertebrates and less studied and understood in invertebrates.

\section{What is behind the differences in cognitive abilities after fight?}

An intriguing question is whether the observed differences in memory capacity between dominants and subordinates could be assigned to a deficit in the former, or an improvement in the latter. The results of the correlation suggest that this would not be a dichotomous phenomenon, but rather a graded one, where differences in the dominance, lead to differences in the subsequent memory.

It is important to consider that all experiments in our study included animals that spent a week in isolation, which was found to impair memory retention. This raises the possibility that the effect of losing a fight facilitates the retention of an aversive memory when isolation conditions tend to have a detrimental effect on it. Thus, isolation and social experience could have opposite effects on memory.

An alternative explanation for a better memory ability of subordinates may be related to their cognitive strategies. Social context constrains subordinates regarding the availability of resources, so it is speculated that low-ranking individuals may have a better predisposition for certain learning tasks (Kummer and Goodall 1985; Reader and Laland 2001). Subordinates may not necessarily be better than dominant in all types of learning, but they may simply be more flexible in their behavior. This can be adaptive, as it increases the chances of survival in situations where resources are monopolized by the dominants.

The ability to flexibly adjust behavioral responses depending on the external conditions might critically affect an individual's fitness in complex dynamic environments. The ability to flexibly solve problems may be related to the species socio-ecological characteristics, which in turn may be associated with cognitive skills. In birds, for example, subordinate individuals evaluate social context and consequently modify their foraging behavior. Particularly, it has been shown that they refrain from eating when higherranking partners are close (i.e. inhibition), but reach for the food as soon as the dominant left (i.e. behavioral flexibility). Moreover, dominants can also directly make subordinates more vulnerable to predation by monopolizing the safest habitats for feeding (Aho et al. 1997; Ekman and Askenmo 1984; Schneider 1984; Suhonen 1993). In this sense, rankrelated differences in site use were found and caused by the presence of dominant: subordinates tended to increase their use of safe sites after the removal of the dominant (Koivula et al. 1994). Further, a study in a freshwater tropical fish evaluated whether the opportunity to learn about the location and availability of food might facilitate food-stealing attempts by males (Hollis et al. 2004). Results showed that subordinates were able to use learned cues to mount highly effective 'sneaky' tactics. Thus, they combined information about previous learning, namely an 'expectancy' of food, with the probability of future attacks, and adjust their food-getting strategy accordingly.

\section{In between: biogenic amines, the link between aggression and memory}

From the results obtained in this work, a question arises regarding the relationship between dominance and memory. That is, what is the mechanism that constitutes a physiological link between dominance status and the consolidation of long-term memory? Aminergic systems are good candidates to mediate in these processes (Huber et al. 1997). Biogenic amines have been implicated as key physiological regulators of aggressive behavior in different animal groups, from mammals to insects (Huber et al. 1997). Various studies in decapod crustaceans, including Neohelice granulata, link serotonin (5HT) with behaviors associated with subordinate status, while octopamine (OA) is linked with behaviors typical of dominant status (Antonsen and Paul 1997; Eisenreich and Szalda-Petree 2015; Momohara et al. 2013; Pedetta et al. 2010).

Regarding mnesic processes, a series of experimental evidence support the idea that octopamine (OA) plays a fundamental role in regulating associative learning processes in insects (Giurfa 2006). Particularly, in Neohelice granulata, the role of octopamine has been studied under the contextsignal memory paradigm (Kaczer and Maldonado 2009). It was found that by injecting animals with OA immediately after training, both the consolidation and reconsolidation phases were affected, while the acquisition and evocation phases were not altered. However, the injection of OA $48 \mathrm{~h}$ before the training session had a memory enhancing effect. Hence, we propose that the mechanisms involved in the establishment of the dominance condition could cause a modification in the recruited circuits during memory consolidation. Specifically, we propose that OA and 5HT could constitute a link between agonistic behavior and differential modulation of the memory of winners and losers. In this sense, agonistic confrontation should cause a variation in the levels of OA and 5HT in the animals or a change in their octopaminergic/serotonergic system.

\section{From lab to field: aggression and behavioral strategies in the crab Neohelice granulata}

Neohelice granulata aggressive behavior has been well characterized in lab conditions. Analyses of size-matched 
male crabs have revealed that they performed conspicuous agonistic behavior and establish winner-loser relationships. However, neither displays of ritualized aggression nor characteristic postures of dominant and subordinate were found. The subordinate animal did not present a submission pattern as it occurs in other decapods (Antonsen and Paul 1997). As well, attacks carried a low risk of injury (no loss of legs or chelae were observed due to autotomy) and most fights were defined within $10 \mathrm{~min}$, establishing a winning and a loser animal. Therefore, we consider that a hierarchical rank would not be established but rather a dominance condition that would be determined based on the relative aggressiveness level of each opponent (Pedetta et al. 2010).

Field observations reveal that these crabs are solitary animals and their limited interactions with conspecifics are aggressive. Interactions mainly occur in the context of burrow disputes between a resident and a wondering crab, behavior which is ultimately associated with matting success (Fathala et al. 2009; Fathala and Maldonado 2011; Sal Moyano et al. 2016). Burrows constitute the epicenter of the crab's surface activity and provide sediment and organic matter supplement (Botto and Iribarne 2000), protection from tides and temperature, access to water, and protection against predators. The mating system of Neohelice granulata is based on the defense of burrows constructed by the large males. These burrows can be used as a sheltered/protected copulatory chamber or for mating purposes (Moyano et al. 2012). By contrast, small males construct burrows as straight tubes, without chambers, and their copulations can occur (1) on the surface, by interception of receptive females, or (2) in burrows of large males (Moyano et al. 2012). Moreover, it has been found that there is a restricted size range in mating pair formation; thus, the largest males in the population may copulate with the largest females inside their burrows with copulation chambers because females look for these burrows, thereby obtaining higher fecundity and the greater reproductive success. The smallest sexually mature males in the population may copulate with the smaller sexually mature females by developing an alternative mating strategy, such as intercepting females on the surface or by occupying empty chambered burrows constructed by large males. This alternative mating strategy could be defined as "cheat mating" because small males avoid energy costs related to the construction of a chambered burrow and cheat females which are looking for large male burrows (Moyano et al. 2016). This mating system developed by small males could be understood as a behavioral flexibility strategy to get access to resources that are mostly monopolized by dominant animals and might be associated with better cognitive abilities for resource exploitation in a potentially dangerous environment.
It has been found that movement within and between habitats in Neohelice granulata is mainly performed by large crabs. More active crabs observed in the field were large males. In contrast, females and juveniles were found to avoid more efficiently catch traps, than large males (Luppi et al. 2013). Authors proposed that this behavioral diversity could be related not only to the vulnerability to predators, but also to the susceptibility of small crabs to be cannibalized by larger males (Luppi et al. 2001) and/or to the higher susceptibility of small crabs to extreme temperature and water loss (Willmer et al. 2009; Mendez Casariego et al. 2011). This finding is in accordance with the observed increase in exploratory activity of dominant animals revealed in our work.

Predation risk by the crab-eater gull is a constant in the life of these animals. However, it is not a predictable pattern. Thus, being able to rapidly change behavior from escape to freezing turns into an important trait for animal's survival. Freezing strategy in small or subordinate animals could represent an optimal defensive behavior since it would entail going unnoticed in the environment when a predator is approaching. Differently, the dominant defensive strategy might account for better eliciting an escape response, as they have better opportunities to reach burrows that are mostly monopolized by them. Although our study was performed in controlled laboratory conditions, the results regarding the modulation of associative memories by fight outcome could imply that some characteristics or behavioral strategies can be better understood by raising the ecological context in which these animals live.

\section{Conclusion}

In what has been said so far, we have repeatedly emphasized the relationships between individuals and the environment, as well as the relationship of animals with members of their species. We understand that the cognitive abilities of an animal cannot be studied without considering the ecological pressures that shape its behavior. Within this framework, this work contributes to approach the complex study of learning and memory according to the social context in which such processes occur, thus expanding the scenario and proposing a more comprehensive vision in the research of such cognitive processes.

Supplementary Information The online version contains supplementary material available at https://doi.org/10.1007/s10071-021-01492-6.

Acknowledgements This work was supported by National Agency of Scientific and Technological Promotion (PICT2013-0412 and PICT2016-0243) to MEP. Authors would like to thank Dr Martín 
Klappenbach, Mariano Boccia and María Krawczyk for his helpful comments on the manuscript and Angel Vidal for technical assistance.

Author contribution MJS: conceptualization, data curation, formal analysis, investigation, writing - original draft, Writing and editing. SAM: investigation, writing and editing. LK: conceptualization, funding acquisition, project administration, resources, supervision, validation, writing - original draft, writing and editing. MEP: conceptualization, funding acquisition, project administration, resources, supervision, validation, writing-original draft, writing and editing.

Funding This work was supported by National Agency of Scientific and Technological Promotion (PICT2013-0412 and PICT2016-0243) to MEP.

Data availability Available upon request.

\section{Declarations}

Conflict of interest The authors declare no conflict of interest.

Ethics approval Experimental procedures are in compliance with the National Institutes of Health Guide for Care and Use of Laboratory Animals (USA) and the Argentinean guidelines on the ethical use of animals. All efforts were made to minimize animal suffering and to reduce the number of animals used.

\section{References}

Adelman M, Chen AY, Aberg A, Neumeister H, Preuss T (2019) Social context influences sensorimotor gating in female African cichlid fish Astatotilapia burtoni. Behav Brain Res 370(March):111925

Aho T, Kuitunen M, Suhonen J, Hakkari T, Jaè A (1997) Effects of male removal on female foraging behavior in the Eurasian treecreeper. Behav Ecol Sociobiol 41:49-53

Ames A (2000) CNS energy metabolism as related to function. Brain Res Rev 34(1-2):42-68

Antonsen B, Paul D (1997) Serotonin and octopamine elicit stereotypical agonistic behaviors in the squat lobster Munida quadrispina (Anomura, Galatheidae). J Comp Physiol A 181:501-510

Arnott G, Elwood RW (2009) Assessment of fighting ability in animal contests. Anim Behav 77(5):991-1004

Barnard CJ, Luo N (2002) Acquisition of dominance status affects maze learning in mice. Behav Proc 60(1):53-59

Beynen AC, Gärtner K, van Zutphen LFM (2003) Standardization of animal experimentation. In: Zutphen LFM, Baumans V, Beynen AC (eds) Principles of laboratory animal science, 2nd edn. Elsevier Ltd, Amsterdam, pp 103-110

Blanchard RJ, McKittrick CR, Blanchard DC (2001) Animal models of social stress: effects on behavior and brain neurochemical systems. Physiol Behav 73(3):261-271

Boogert NJ, Reader SM, Laland KN (2006) The relation between social rank, neophobia and individual learning in starlings. Anim Behav 72(6):1229-1239

Botto F, Iribarne O (2000) Contrasting effects of two burrowing crabs (Chasmagnathus granulata and Uca uruguayensis) on sediment composition and transport in estuarine environments. Estuar Coast Shelf Sci 51:141-151

Brudzynski SM, Mercier AJ, Drozdz JK, Viscek J (2006) Behavioral responses of crayfish to a reflective environment. J Crustac Biol 26(4):463-473
Bunnell BN, Kenshalo DP, Czerny P, Allen JD (1979) Performance correlates of social behavior and organization: Effects of group formation on operant performance in rhesus monkeys $(M$. mulatta). Primates 20(2):197-210

Burrell BD, Sahley CL (2001) Learning in simple systems. Curr Opin Neurobiol 11(6):757-764

Cacioppo JT, Hawkley LC (2009) Perceived social isolation and cognition. Trends Cogn Sci 13(10):447-454

Canero E, Hermitte G (2014) New evidence on an old question: is the "fight or flight" stage present in the cardiac and respiratory regulation of decapod crustaceans? J Physiol Paris 108(2-3):174-186

Chalmeau R, Gallo A (1993) Social constraints determine what is learned in the chimpanzee. Behav Proc 28(3):173-179

Colas-Zelin D et al (2012) The imposition of, but not the propensity for, social subordination impairs exploratory behaviors and general cognitive abilities. Behav Brain Res 232:294-305

Cromarty S, Mello J, Kass-Simon G (1999) Time in residence affects escape and agonistic behavior in adult male American lobsters. Biol Bull 196(1):105-112

Dalesman S, Lukowiak K (2011) Social snails: The effect of social isolation on cognition is dependent on environmental context. J Exp Biol 214(24):4179-4185

David M, Auclair Y, Cézilly F (2011) Personality predicts social dominance in female zebra finches, Taeniopygia guttata, in a feeding context. Anim Behav 81(1):219-224. https://doi.org/10.1016/j. anbehav.2010.10.008

del Velle Fathala M, Maldonado H (2011) Shelter use during exploratory and escape behaviour of the crab Chasmagnathus granulatus: a field study. J Ethol 29(2):263-273

Dingemanse N, de Goede P (2004) The relation between dominance and exploratory behavior is context-dependent in wild great tits. Behav Ecol 15:1023-1030

Drea CM (1998) Social context affects how rhesus monkeys explore their environment. Am J Primatol 44(3):205-214

Drent PJ, Boon A, Verbeek MEM (1996) Exploration, aggressive behaviour and dominance in pair-wise confrontations of juvenile male great tits. Behaviour 133(11):945-963

Dukas R (1999) Costs of memory: Ideas and predictions. J Theor Biol 197(1):41-50

Eggert A-K, Otte T, Müller JK (2008) Starving the competition: a proximate cause of reproductive skew in burying beetles (Nicrophorus vespilloides). Proc Biol Sci 275(1650):2521-2528

Eisenreich BR, Szalda-Petree A (2015) Behavioral effects of fluoxetine on aggression and associative learning in Siamese fighting fish (Betta splendens). Behav Proc 121:37-42

Ekman JB, Askenmo CEH (1984) Social rank and habitat use in willow tit groups. Anim Behav 32(2):508-514

Fathala M, Iribarren L, Kunert MC, Maldonado H (2009) A field model of learning: 1. Short-term memory in the crab Chasmagnathus granulatus. J Comp Physiol A 196(1):61-75

Fitchett A, Collins S (2005) Subordinate male mice show long-lasting differences in spatial learning that persist when housed alone. Neurobiol Learn Mem 84(3):247-251

Francia N, Cirulli F, Chiarotti F, Antonelli A, Aloe L, Alleva E (2006) Spatial memory deficits in middle-aged mice correlate with lower exploratory activity and a subordinate status: role of hippocampal neurotrophins. Eur J Neurosci 23(3):711-728

Fustiñana M, Tano M, Romano A, Pedreira M (2013) Contextual Pavlovian conditioning in the crab Chasmagnathus. Anim Cogn $16(2): 255-272$

Giurfa M (2006) Associative learning: the instructive function of biogenic amines. Curr Biol 16(20):R892-R895 (Cell Press)

Gluck JP, Harlow HF (1971) The effects of deprived and enriched rearing conditions on later learning: A review. In: LE Jarrard (ed) Cognitive processes of non human primates. Academic Press, New York, pp 103-119 
Green MR, McCormick CM (2013) Effects of social instability stress in adolescence on long-term, not short-term, spatial memory performance. Behav Brain Res 256:165-171

Guiasu R, Dunham D (1999) Aggressive interactions between the crayfishes Cambarus bartonii bartonii and C. robustus (Decapoda: Cambaridae): interspecific and intraspecific contests. J Crustac Biol 19(1):131-146

Hep Y, Pérez-Cuesta LM, Maldonado H, Pedreira ME (2010) Extinction memory in the crab Chasmagnathus: recovery protocols and effects of multi-trial extinction training. Anim Cogn 13:391-403

Hepp Y, Salles A, Carbo-Tano M, Pedreira ME, Freudenthal R (2016) Surface expression of NMDA receptor changes during memory consolidation in the crab Neohelice granulata. Learn Mem 23(8):427-434

Hernández-Falcón J, Basu AC, Govindasamy S, Kravitz EA (2005) Changes in heart rate associated with contest outcome in agonistic encounters in lobsters. Cell Mol Neurobiol 25(2):329-343

Hofmann HA, Benson ME, Fernald RD (1999) Social status regulates growth rate: consequences for life-history strategies. Proc Natl Acad Sci USA 96(24):14171-14176

Hollis KL, Langworthy-Lam KS, Blouin LA, Romano MC (2004) Novel strategies of subordinate fish competing for food: learning when to fold. Anim Behav 68(5):1155-1164

Howell D (1987) Statistical methods for psychology PWS-Kent. Seventh edition, Boston, MA

Huber R, Orzeszyna M, Pokorny N, Kravitz EA (1997) Biogenic amines and aggression: experimental approaches in crustaceans. Brain Behav Evol 50(1):60-68

Humphrey N (1976) The social function of intellect. Grow Points Ethol 1970:303-317

Huntingford F, Turner A (1987) Animal Conflict. Chapman \& Hall, London

Iribarne O, Bortolus A, Botto F (1997) Between-habitat differences in burrow characteristics and trophic modes in the southwestern Atlantic burrowing crab Chasmagnathus granulata. Mar Ecol Prog Ser 155:137-145. https://doi.org/10.3354/meps155137

Jaumann S, Scudelari R, Naug D (2013) Energetic cost of learning and memory can cause cognitive impairment in honeybees. Biol Lett 9(4):20130149

Kaczer L, Maldonado H (2009) Contrasting role of octopamine in appetitive and aversive learning in the crab Chasmagnathus. PLoS ONE 4(7):e6223

Kaczer L, Pedetta S, Maldonado H (2007) Aggressiveness and memory: subordinate crabs present higher memory ability than dominants after an agonistic experience. Neurobiol Learn Mem 87(1):140-148

Karavanich C, Atema J (1998) Individual recognition and memory in lobster dominance. Anim Behav 56(6):1553-1560

Keeney AJ, Hogg S (1999) Behavioural consequences of repeated social defeat in the mouse: preliminary evaluation of a potential animal model of depression. Behav Pharmacol 10(8):753-764

Keynan O, Ridley AR, Lotem A (2015) Social foraging strategies and acquisition of novel foraging skills in cooperatively breeding Arabian babblers. Behav Ecol 26(1):207-214

Keynan O, Ridley AR, Lotem A (2016) Task-dependent differences in learning by subordinate and dominant wild Arabian babblers. Ethology 122(5):399-410

Klappenbach M, Maldonado H, Locatelli F, Kaczer L (2012) Opposite actions of dopamine on aversive and appetitive memories in the crab. Learn Mem 19(2):73-83

Koivula K, Lahti K, Rytko“nen S, Orell M (1994) Do subordinates expose themselves to predation? Field experiments on feeding site selection by willow tits. J Avian Biol 25:178-183

Kravitz EA, Huber R (2003) Aggression in invertebrates. Curr Opin Neurobiol 13: 736-743.https://doi.org/10.1016/j.conb.2003.10.003

Kummer H, Goodall J (1985) Conditions of innovative behaviour in primates. Phil Trans R Soc B Biol Sci 308:203e214

Langley EJG, Van Horik JO, Whiteside MA, Madden JR (2018b) Group social rank is associated with performance on a spatial learning task. Royal Soc Open Sci 5(2):1-9
Langley EJG, Van Horik JO, Whiteside MA, Beardsworth CE, Madden JR (2018). The relationship between social rank and spatial learning in pheasants, Phasianus colchicus: Cause or consequence? PeerJ, 2018(11)

Laughlin SB, de Ruyter van Steveninck RR, Anderson JC (1993) The metabolic cost of neural information. Nat Neurosci 1:36-41

Laukens D, Brinkman BM, Raes J, De Vos M, Vandenabeele P (2016) Heterogeneity of the gut microbiome in mice: guidelines for optimizing experimental design. FEMS Microbiol Rev 40(1):117-132

Loken E, Gelman A (2017) Measurement error and the replication crisis. Science 355:584-585

Lopez MF, Doremus-Fitzwater TL, Becker HC (2011) Chronic social isolation and chronic variable stress during early development induce later elevated ethanol intake in adult C57BL/6J mice. Alcohol 45(4):355-364

Luppi Tomás A, Rodriguez EM (2020) Neohelice granulata, a model species for studies on crustaceans, volume I: life history and ecology. Cambridge Scholars Publishing, p 401. ISBN:978-1-5275-5003-2

Luppi TA, Spivak ED, Anger K (2001) Experimental studies on predation and cannibalism of the settlers of Chasmagnathus granulata and Cyrtograpsus angulatus (Brachyura: Grapsidae). J Exp Mar Biol Ecol 265:29-48

Luppi T, Bas C, Méndez Casariego A, Albano M, Lancia J, Kittlein M, Rosenthal A, Farías N, Spivak E, Iribarne O (2013) The influence of habitat, season and tidal regime in the activity of the intertidal crab Neohelice (=Chasmagnathus) granulata . Helgol Mar Res 67(1):1-15

Makinodan M, Ikawa D, Miyamoto Y, Yamauchi J, Yamamuro K, Yamashita Y, Toritsuka M, Kimoto S, Okumura K, Yamauchi T, Fukami S, Yoshino H, Wanaka A, Kishimoto T (2016) Social isolation impairs remyelination in mice through modulation of IL-6. FASEB J 30(12):4267-4274

Maldonado H (2002). Crustacean as model to investigate memory illustrated by extensive behavioral and physiological studies in Chasmagnathus. In: Wiese K (ed) The crustacean nervous system. Springer, Berlin, pp 314-327

Maleszka J, Barron AB, Helliwell PG, Maleszka R (2009) Effect of age, behaviour and social environment on honey bee brain plasticity. J Comp Physiol A 195(8):733-740

Manca R, Marco M De, Venneri A (2020) The impact of COVID-19 infection and enforced prolonged social isolation on neuropsychiatric symptoms in older adults with and without dementia : a review. Front Psychiat 11:1086

Maruska KP, Fernald RD (2012) Contextual chemosensory urine signaling in an African cichlid fish. J Exp Biol 215(1):68-74

Matzel LD, Kolata S, Light K, Sauce B (2017) The tendency for social submission predicts superior cognitive performance in previously isolated male mice. Behav Proc 134:12-21

May HY, Mercier AJ (2007) Duration of socialization influences responses to a mirror: responses of dominant and subordinate crayfish diverge with time of pairing. J Exp Biol 210(Pt 24):4428-4436

McIntosh AL, Ballard TM, Steward LJ, Moran PM, Fone KCF (2013) The atypical antipsychotic risperidone reverses the recognition memory deficits induced by post-weaning social isolation in rats. Psychopharmacology 228(1):31-42

Medendorp WE, Petersen ED, Pal A, Wagner LM, Myers AR, Hochgeschwender U, Jenrow KA (2018) Altered behavior in mice socially isolated during adolescence corresponds with immature dendritic spine morphology and impaired plasticity in the prefrontal cortex. Front Behav Neurosci 12:87

Mendez Casariego A, Luppi T, Iribarne O, Daleo P (2011) Increase of organic matter transport between marshes and tidal flats by the burrowing crab Neohelice (Chasmagnathus) 
granulata Dana in SW Atlantic salt marshes. J Exp Mar Biol Ecol 401(1-2):110-117

Mery F, Kawecki TJ (2005) A cost of long-term memory in Drosophila. Science 308(5725):1148

Momohara Y, Kanai A, Nagayama T (2013) Aminergic control of social status in crayfish agonistic encounters. PLoS ONE 8(9):e74489

Monlenn S, Duque A, Vinader-Caerols C (2015) Inhibitory avoidance learning in CD1 mice: effects of chronic social defeat stress. Behav Proc 115:64-69

Moyano MPS, Gavio MA, Luppi T (2012) Mating system of the burrowing crab Neohelice granulata (Brachyura: Varunidae) in two contrasting enviroments: effect of burrow architecture. Artic Mar Biol 159:1403-1416

Moyano MP, Lorusso M, Nuñez J, Ribeiro P, Gavio MA, Luppi T (2016) Male size-dependent dominance for burrow holding in the semiterrestrial crab Neohelice granulata: multiple tactics used by intermediate-sized males. Behav Ecol Sociobiol 70(9):1497-1505

Moyers SC, Adelman JS, Farine DR, Moore IT, Hawley DM (2018) Exploratory behavior is linked to stress physiology and social network centrality in free-living house finches (Haemorhous mexicanus). Horm Behav 102(November 2017):105-113

Nelson R (2005) Biology of aggression. Oxford University Press

Okada R, Matsumoto K, Tsushima R, Fujiwara H, Tsuneyama K (2014) Social isolation stress-induced fear memory deficit is mediated by down-regulated neuro-signaling system and Egr-1 expression in the brain. Neurochem Res 39(5):875-882

Pedetta S, Kaczer L, Maldonado H (2010) Individual aggressiveness in the crab Chasmagnathus: influence in fight outcome and modulation by serotonin and octopamine. Physiol Behav 101(4):438-445

Pereyra P, Saraco M, Maldonado H (1999) Decreased response or alternative defensive strategy in escape: two novel types of long-term memory in the crab Chasmagnathus. J Comp Physiol 184:301-310

Plagg B, Engl A, Piccoliori G, Eisendle K (2020) Prolonged social isolation of the elderly during COVID-19: between benefit and damage. Arch Gerontol Geriatr 89:104086

Popp JL, DeVore 1 (1979) Aggressive competition and social dominance theory: synopsis. In: Hamburg DA, McCown ER (eds) The great Apes. Benjamin/Cummings, Menlo Park, CA

Pravosudov VV, Lavenex P, Omanska A (2005) Nutritional deficits during early development affect hippocampal structure and spatial memory later in life. Behav Neurosci 119(5):1368-1374

Reader S, Laland K (2001) Primate innovation: sex, age and social rank differences. Int J Primatol 22(5):787-805

Reedijk M, Odorcic S, Zhang H, Chetty R, Tennert C, Dickson BC, Lockwood G, Gallinger S, Egan SE (2009) NIH Public Access 33(6):1223-1229

Rescorla RA (1988) Pavlovian conditioning: it's not what you think it is. Am Psychol 43:151-160

Robson MA, Miles DB (2000) Locomotor performance and dominance in male Tree Lizards Urosaurus ornatus. Fun Ecol 14(3):338-344

Rodriguez EM, Luppi TA (2020) Neohelice granulata, a Model Species for Studies on Crustaceans, Volume II: Anatomy and Physiology.

Rosenthal R, Rosnow RL (1985) Contrast analysis: focused companrisons in the analysis of variance. Cambridge Umversity Press, New York

Schneider KJ (1984) Dominance, predation, and optimal foraging in white-throated sparrow flocks. Ecology 65(6):1820-1827

Sepulveda-Loyola W, Rodriguez-Sanchex I, Perez-Rodriguez P, Ganz F, Torralba R, Oliviera DV, Rodri-guez-Manas L (2020) Impact of social isolation due to COVID-19 on health in older people: mental and physical effects and recommendations. J Nutr Health Aging
Shams S, Chatterjee D, Gerlai R (2015) Chronic social isolation affects thigmotaxis and whole-brain serotonin levels in adult zebrafish. Behav Brain Res 292:283-287

Snell-Rood EC, Davidowitz G, Papaj DR (2011) Reproductive tradeoffs of learning in a butterfly. Behav Ecol 22(2):291-302

Song C-K, Herberholz J, Edwards DH (2006) The effects of social experience on the behavioral response to unexpected touch in crayfish. J Exp Biol 209(Pt 7):1355-1363

Spivak ED (1997) Cangrejos estuariales del Atlántico sudoccidental $\left(25^{\circ}-41^{\circ} \mathrm{S}\right)$ (Crustacea: Decapoda: Brachyura). Investig Mar 25:105-120

Spivak ED (2010) The crab Neohelice (=Chasmagnathus) granulata: an emergent animal model from emergent countries. Helgol Mar Res 64(3):149-154

Spivak E, Anger K, Luppi T, Bas C, Ismael D (1994) Distribution and habitat preferences of two grapsid crab species in Mar Chiquita Lagoon (Province of Buenos Aires, Argentina). Helgolander wissenschaftliche Meeresuntersuchungen 48:59-78

Spritzer M, Meikle D, Solomon N (2004) The relationship between dominance rank and spatial ability among male meadow voles (Microtus pennsylvanicus). J Comp Psychol 118(3):332-339

Suhonen J (1993) Predation risk influences the use of foraging sites by tits. Ecology 74(4):1197-1203

Technau GM (2007) Fiber number in the mushroom bodies of adult Drosophila melanogaster depends on age, sex and experience. J Neurogenet 21(4):183-196

Trannoy S, Kravitz EA (2015) Learning and memory during aggression in Drosophila: handling affects aggression and the formation of a "loser" effect. J Nat Sci 1(3):e56

Valzelli L (1973) The 'isolation syndrome' in mice. Psychopharmacologia 31: 305-320

van Zutphen LFM, Baumans V, Beynen AC (eds) (1993) Principles of laboratory animal science. A contribution. To the humane use and care of animals and to the quality of experimental results. Elsevier, Amsterdam, pp 389

Voelkl B, Altman NS, Forsman A, Forstmeier W, Gurevitch J, Jaric I, Karp NA, Kas MJ, Schielzeth H, Van de Casteele T, Würbel H (2020) Reproducibility of animal research in light of biological variation. Nat Rev Neurosci

Vye C, Cobb J, Bradley T, Gabbay J, Genizi A, Karplus I (1997) Predicting the winning or losing of symmetrical contests in the American lobster Homarus americanus (Milne-Edwards). J Exp Mar Biol Ecol 217(1):19-29

Wang B, Wu Q, Lei L, Sun H, Michael N, Zhang X, Wang Y, Zhang Y, Ge B, Wu X, Wang Y, Xin Y, Zhao J, Li S (2019) Long-term social isolation inhibits autophagy activation, induces postsynaptic dysfunctions and impairs spatial memory. Exp Neurol 311(September 2018):213-224

Willmann R, De Luca A, Benatar M, Grounds M, Dubach J, Raymackers JM, Nagaraju K (2012) Enhancing translation: guidelines for standard pre-clinical experiments in $\mathrm{mdx}$ mice. Neuromuscul Disord 22(1):43-49

Willmer P, Graham S, Johnston I (2009) Environmental physiology of animals, 2nd edn. Blackwell, Malden, MA, p 644

Wilson E (1975) 1975 Sociobiology: the new synthesis. Harvard University Press, Cambridge, Massachusetts

Yeh SR, Fricke RA, Edwards DH (1996) The effect of social experience on serotonergic modulation of the escape circuit of crayfish. Science (New York, N.Y.) 271(5247):366-369

Yeh S-R, Musolf BE, Edwards DH (1997) Neuronal adaptations to changes in the social dominance status of crayfish. J Neurosci 17(2):697-708

Publisher's Note Springer Nature remains neutral with regard to jurisdictional claims in published maps and institutional affiliations. 